Aus der Abteilung Kinder- und Jugendpsychiatrie und Psychotherapie

(Prof. Dr. med. A. Rothenberger)

im Zentrum Psychosoziale Medizin

der Medizinischen Fakultät der Universität Göttingen

\title{
Impact of obsessive-compulsive behavior on the psychopathological profile of children with chronic tic disorder and attention-deficit hyperactivity disorder
}

\author{
INAUGURAL-DISSERTATION \\ zur Erlangung des Doktorgrades \\ der Medizinischen Fakultät \\ der Georg-August-Universität zu Göttingen
}

vorgelegt von Finnja Bielas, geborene Schultze

aus Bremen

Göttingen 2012 
Dekan: Prof. Dr. med. M. P. Schön

1. Berichterstatter: Prof. Dr. med. A. Rothenberger

2. Berichterstatter: Prof. Dr. med. Spitzer

3. Berichterstatterin: Prof. Dr. rer. nat. Virsik-Köpp

Tag der mündlichen Prüfung: 26.11.2012 


\section{Contents}

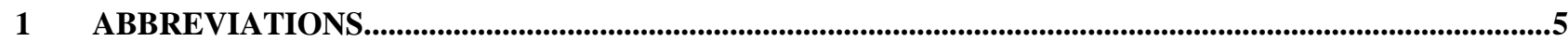

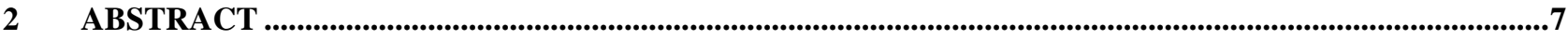

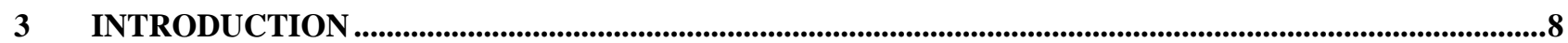

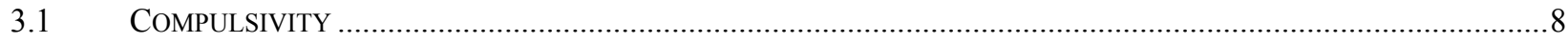

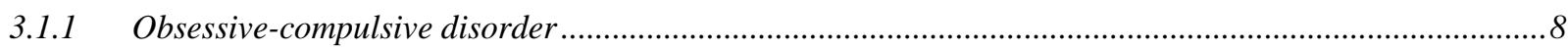

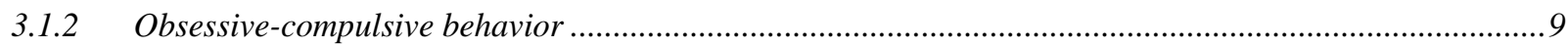

3.1.3 Symptom-continuity ............................................................................................................................

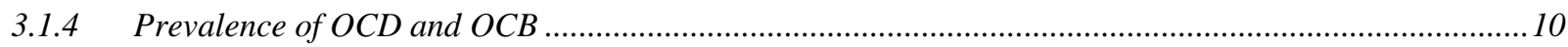

3.1.5 Time of onset, gender-related aspects and course of $O C D$ and $O C B$.....................................................12

3.1.6 Assessment of pediatric OCD/OCB.................................................................................................13

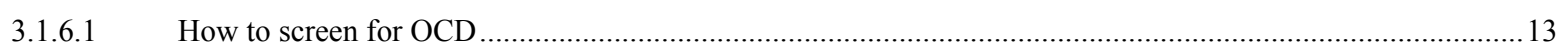

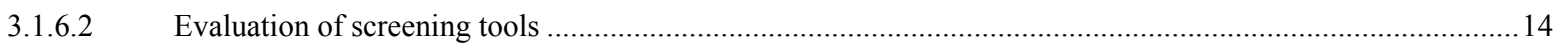

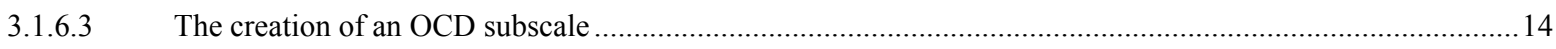

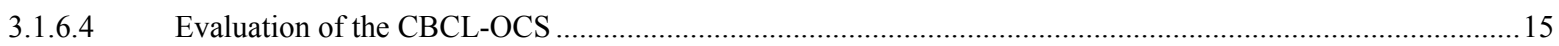

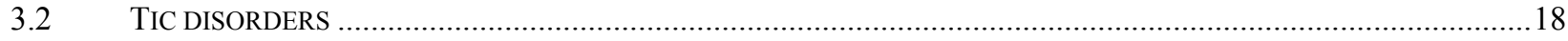

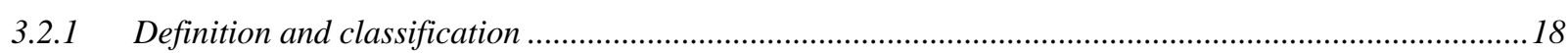

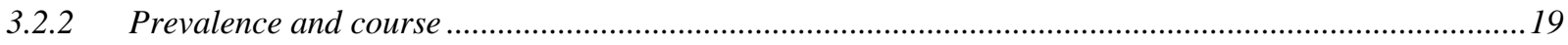

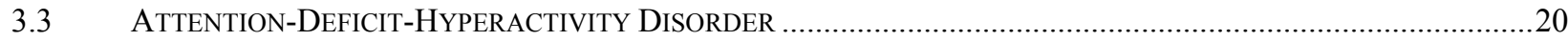

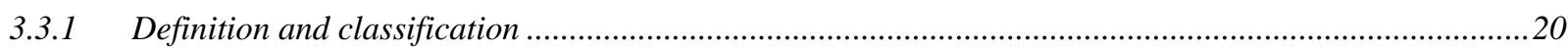

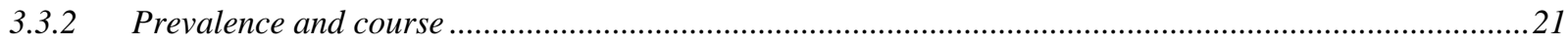

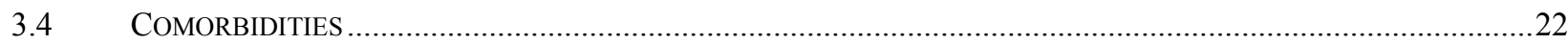

3.4.1 Coexisting $O C D$ in children and adolescents with $A D H D$...............................................................22

3.4.2 Coexisting OCB in children and adolescents with $A D H D$.................................................................23

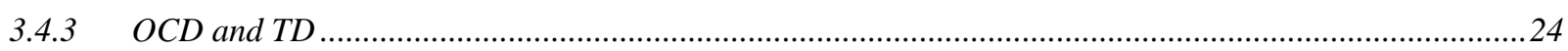

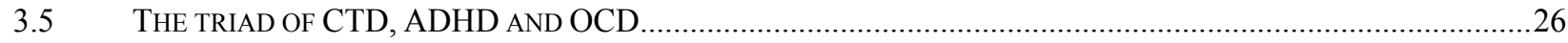

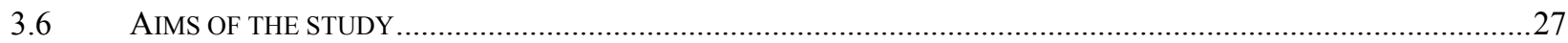

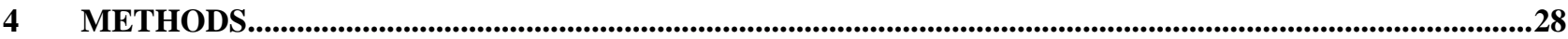

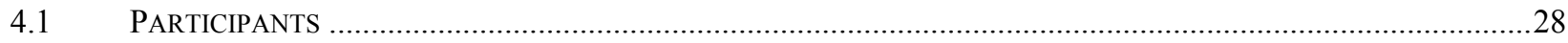

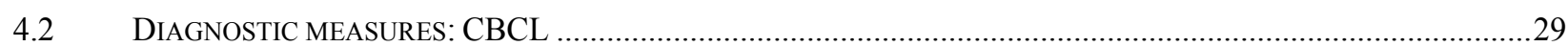

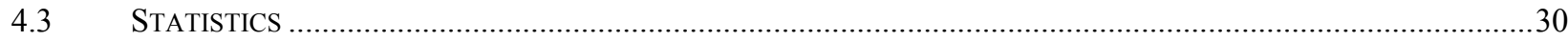

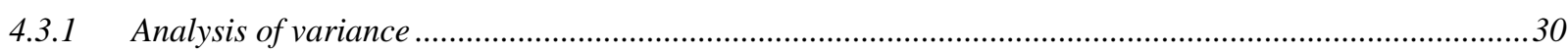

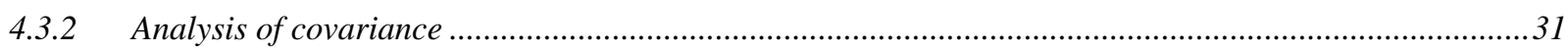

4.3.3 Covariates applied in the ANCOVAs ..............................................................................................

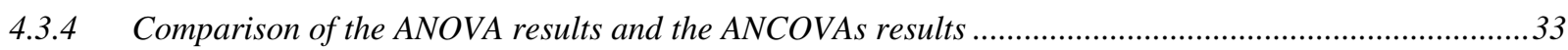

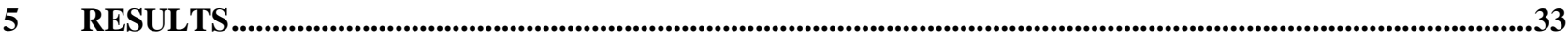

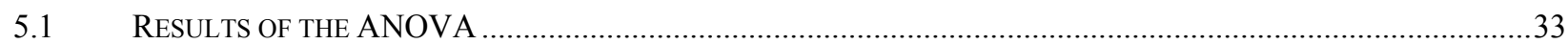

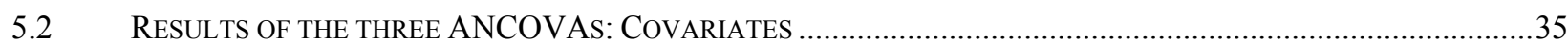


5.3 COMPARING MAIN EFFECTS FROM THE 2X2 ANOVA TO THOSE OF THE THREE 2X2 ANCOVAS IN TERMS OF THE FACTOR CTD

5.4 COMPARING MAIN EFFECTS FROM THE 2X2 ANOVA TO THOSE OF THE THREE 2X2 ANCOVAS IN TERMS OF

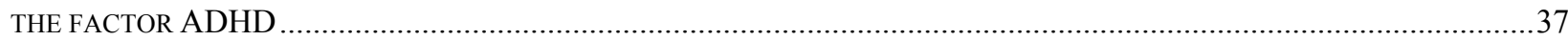

5.5 RESULTS OF THE FIRST ANCOVA WITH THE "NELSON SCORE” AS COVARIATE..............................................

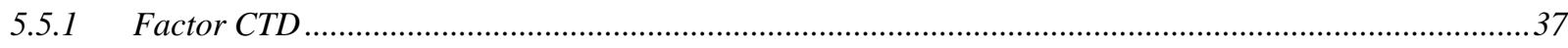

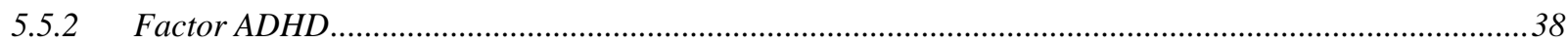

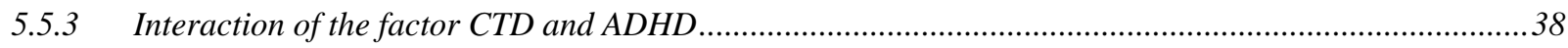

5.6 RESULTS OF THE SECOND ANCOVA WITH THE “MOLL SCORE” AS COVARIATE .........................................38

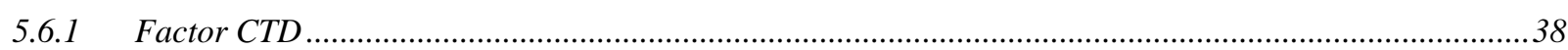

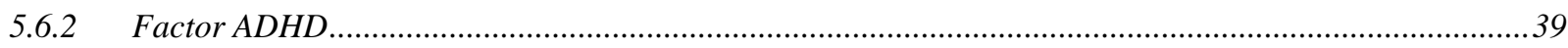

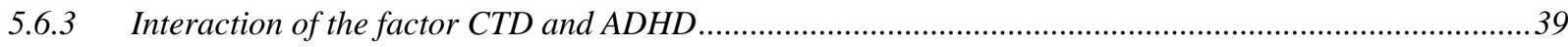

5.7 RESULTS OF THE THIRD ANCOVA WITH THE “STORCH SCORE” AS COVARIATE.........................................40

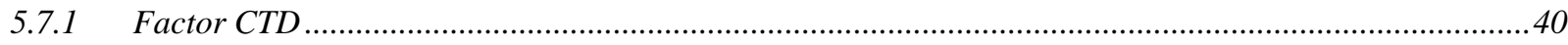

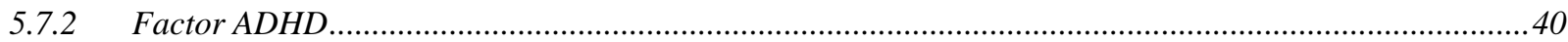

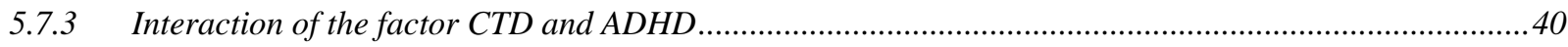

5.8 COMPARISON OF CHANGES IN PSYCHOPATHOLOGY PROFILES PROVOKED BY THE APPLICATION OF COVARIATES IN THE GROUPS INCLUDING CTD AS A FACTOR VS. GROUPS INCLUDING ADHD AS A FACTOR ...................................4

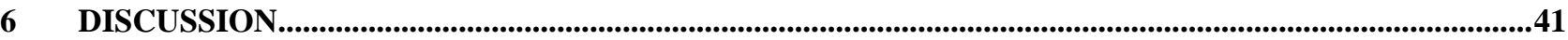

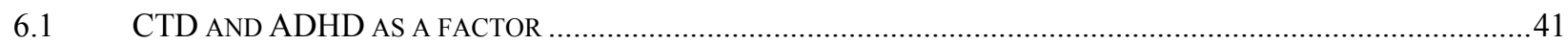

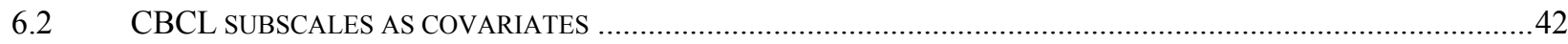

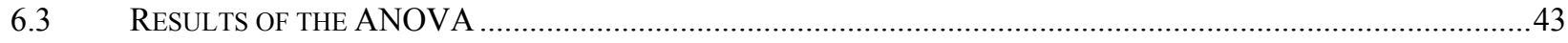

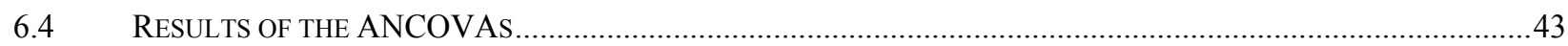

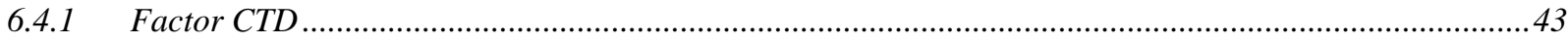

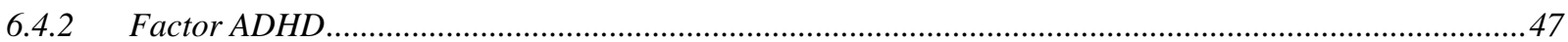

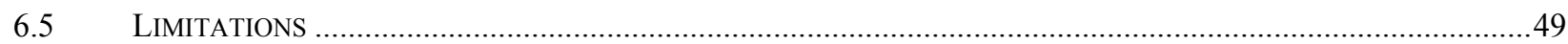

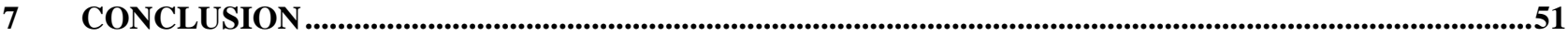

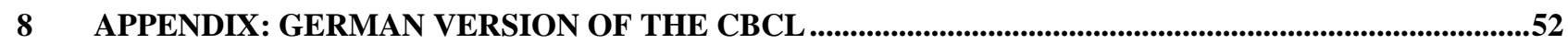

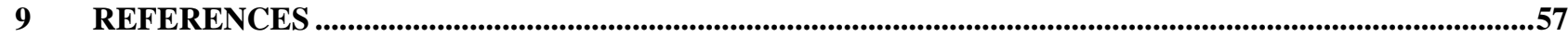




\section{Abbreviations}

ADHD

ANCOVA

ANOVA

CART

CBCL

CBCL-OCS

CFA

CPO group

CTD

CY-BOCS

DIS

DSM-III

DSM-III-R

DSM-IV

DSM-IV-TR

HD

ICD-10

IQ

LCA

LOI-CV

M

$\mathrm{n}$

NPV

OCB

OCD

OCS

PPV

PR

ROC attention-deficit-hyperactivity disorder

analysis of covariance

analyses of variance

classification and regression trees

Child Behavior Checklist

obsessive-compulsive disorder subscale of the CBCL

confirmatory factor analysis

a sample recruited from regular child and adolescent psychiatric outpatient clinics

chronic tic disorders

Children's Yale-Brown Obsessive-Compulsive Scale

Diagnostic Interview Schedule

Diagnostic and Statistical Manual of Mental Disorders, Third Edition

Diagnostic and Statistical Manual of Mental Disorders, Third Edition,

Revised

Diagnostic and Statistical Manual of Mental Disorders, Fourth Edition

Diagnostic and Statistical Manual of Mental Disorders, text revision of the fourth edition

hyperkinetic disorder

International Classification of Diseases

intelligence quotient

latent class analysis

Leyton Obsessional Inventory-Child Version

mean

number of subjects

negative predictive value

obsessive-compulsive behavior

obsessive-compulsive disorder

obsessive-compulsive symptoms

positive predictive value

percentile rank

receiver operating characteristic curve analysis 
SD

SPSS

SS group

TD

TS

TSSS

YGTSS standard deviation

Statistical Package for the Social Sciences

a normative school sample

tic disorders

Tourette syndrome

Tourette Syndrome Severity Scale

Yale Global Tic Severity Scale 


\section{Abstract}

Objective: In child and adolescent psychiatry, a symptom can be caused by a single disorder or the coexistence of several ones.

The present study was conducted to replicate and extend previous phenomenological studies concerning the overlap of psychopathologies in children with chronic tic disorders (CTD) + obsessive-compulsive behavior (OCB) and attention-deficit-hyperactivity disorder (ADHD) + OCB. Taking into consideration the interactions between coexisting disorders and the difficulty of differentiating their contributions to psychopathology, we tested the disorder entities for the main contributing factor of psychopathology. The aim of our study was to ascertain the contribution of OCB to the psychopathology of children with CTD or ADHD.

Method: In this study, we used data from a previously described sample, which consisted of children referred to the outpatient clinic of the Department of Child and Adolescent Psychiatry at the University of Goettingen for routine clinical assessment. Four large groups, matching for age and gender, were built: 112 patients with CTD-only, 129 patients with ADHD-only, 82 patients with CTD+ADHD, and 144 healthy controls. Their psychopathological profiles were assessed with the Child Behavior Checklist (CBCL), one of the best studied questionnaires in psychiatric research for the evaluation of dimensional psychopathology in children and adolescents. The impact of OCB was measured by three separate analyses of covariance (ANCOVAs). In each one, a different OCB score served as a covariate. The OCB scores consisted of various items of the CBCL. The results of the ANCOVAs were then compared to the main effects for CTD and ADHD when OCB was not included.

Results: The most prominent alteration due to the inclusion of OCB as a covariate was seen in the main effects for CTD. In contrast, in the main effects for ADHD only a small alteration resulted from the ANCOVA using OCB as a covariate. These results indicate that OCB clearly contributes to the psychopathology associated with CTD, while ADHD-related symptoms are less influenced by OCB.

Discussion: The hypothesis according to which $\mathrm{OCB} / \mathrm{OCD}$ has a main effect on the psychopathology of children with CTD was confirmed. The additional hypothesis according to which OCB/OCD symptoms also make a contribution to the psychopathology of children with ADHD was also confirmed.

Conclusion: The psychopathology of the children suffering from TS+ADHD is complex. In order to optimize treatment, it is essential to identify and evaluate the disorder that makes the main contribution. Accordingly, our results accentuate the importance of a careful assessment of 
broadband psychopathology, especially for further screening of $\mathrm{OCB} / \mathrm{OCD}$ in patients with $\mathrm{CTD}$ and/or ADHD.

\section{Introduction}

\subsection{Compulsivity}

\subsubsection{Obsessive-compulsive disorder}

The characteristic features of this disorder are recurrent obsessions and/or compulsions. The Diagnostic and Statistical Manual of Mental Disorders (DSM)-IV defines obsessions as persistent ideas, thoughts, impulses or images that are experienced as intrusive or inappropriate and that cause marked distress or anxiety (American-Psychiatric-Association 1994). Obsessions often include fears about contamination, repetitive doubt, need for symmetry, aggressive or unpleasant impulses, and sexual imagery. Individuals who suffer from obsessions regularly try to ignore or suppress them. Their attempts are often unsuccessful and lead to neutralizing behaviors, known as compulsions. Compulsions are described as repetitive behaviors, which are intended, purposeful and often consist in washing, cleaning, ordering, counting and checking. They do not to provide pleasure or gratification and are used to prevent or reduce distress or anxiety (AmericanPsychiatric-Association 1994). The diagnostic criteria for obsessive-compulsive disorder (OCD) in DSM-IV and International Classification of Diseases (ICD)-10 (World Health Organisation 1996) include recurrent obsessions or compulsions, which cause distress, are time-consuming, or interfere with routine functioning. To accord with the ICD-10 criteria, obsessions have to be recognized as own and involuntary thoughts. Obsessions and/or compulsions must also be recognized as excessive or unreasonable, and at least one obsession and/or compulsion that is unsuccessfully resisted must be present (Walitza et al. 2011). In order to fulfill the DSM-IV diagnostic criteria, children will lack insight into the inappropriateness of their obsessions and/or compulsions, although they do not necessarily have to put up any resistance to them (Sass et al. 2003, Wewetzer et al. 2007). In a study by Valleni-Basile et al. 55\% of the patients suffered from both obsessions and compulsions, while $26 \%$ were affected by compulsions only and $19 \%$ suffered merely from obsessions (Valleni-Basile et al. 1994). In the current DSM-IV classification OCD belongs to the category of anxiety disorders, whereas in the ICD-10 OCD and anxiety disorders are separate categories. By this definition, OCD is distressful and in many cases coupled with disability. Although obsessions are described as causing more distress than compulsions (Cath et al. 2000), the suppression of compulsions leads to an increase in distress and anxiety (Wewetzer et al. 2007). Many patients are ashamed of their 
symptoms and fear rejection by others (Ivarsson and Larsson 2008). As a result they tend to be secretive about the sometimes bizarre and mostly irrational nature of their symptoms.

\subsubsection{Obsessive-compulsive behavior}

The term obsessive-compulsive behavior (OCB) is often used to describe subclinical or non-clinical OCD. The characteristics of OCB are often compared to diagnostic criteria fulfilling OCD. In other studies the expression obsessive-compulsive symptoms (OCS) is understood as an equivalent. To avoid confusion, we will always refer to OCB in our study. Both definitions are complicated by inconsistent classification of participants in analogue research. The differentiation between abnormal and normal obsessive symptoms is complicated given the fact that some symptoms may be developmentally appropriate and possibly will resolve with age (Berg et al. 1988). Most children show normal age-dependent OCBs, such as bedtime rituals or collecting (March and Leonard 1996), especially between the ages of two and four years (Wewetzer et al. 2007). These behaviors normally disappear by the time the child is eight years old (Leonard et al. 1990).

\subsubsection{Symptom-continuity}

For compulsions Apter et al. suggested the existence of continuity between few ideotypical symptoms linked with minimal severity and a symptom diversity associated with severe impairment (Apter et al. 1996). Gibbs agreed, concerning different severity in OCD patients and non-clinical groups. Further he emphasized the importance of content, assuming that washing/cleaning compulsions are more frequent in treated populations than in non-clinical groups, because they are more time-consuming and disruptive and therefore easier to recognize (Gibbs 1996). According to Simonds and Elliott the main difference after severity appears to be the interpretation of symptoms and type and efficacy of coping strategies (Simonds and Elliott 2001). Moreover Muris et al. supposed a possible differentiation between abnormal and normal rituals based on their frequency, intensity, association with negative affect, possible resistance against it and the amount of distress caused (Muris et al. 1997). They also found more "washing", "cleaning", and "ordering" among OCD patients, whereas "magical" protective behaviors were more frequent in normal participants. Since differences in terms of content between abnormal and normal rituals appeared small they also indicated the existence of continuity between abnormal and normal compulsions (Muris et al. 1997). Concerning symptom differentiation, Stein et al. noted that participants who did not meet diagnostic criteria usually had either obsessions or compulsions. Only one third exhibited both 
(Stein et al. 1997). In contrast, Burns et al. concluded that the amount of distress seems to be relevant for the ability to meet criteria rather than the absolute number of reported obsessions and compulsions (Burns et al. 1995). Alternatively the content of intrusive cognitions as symptom dimension may differentiate OCD patients and non-clinical patients. Non-patient samples less often reported obsessions with violent, aggressive or sexual themes, as well as fewer thoughts of contamination or disease (Purdon and Clark 1993). Also Rassin and Muris indicated significant differences in topic between clinical obsessions and their subclinical counterparts (Rassin and Muris 2007). Still previous research by Rachman and de Silva had assumed that normal and abnormal obsessions are similar in content and that the topic is irrelevant for the possible development of clinical obsession (Rachman and De Silva 1978). However, it has also been mentioned that it is not the existence or content of intrusive thoughts that differentiates, but the way in which they are appraised and the consequences of this appraisal (Simonds and Elliott 2001). Concerning recurrent thoughts, continuity between normal intrusive thoughts and clinical obsessions was stated even before (Salkovskis 1989). Gibbs indicated that on measures of psychopathology and coexisting cognitive dysfunction non-clinical obsessive-compulsives appear to fall between patients and controls (Gibbs 1996). Another study also suggested that subclinical OCD holds the middle ground between full-blown OCD and insufficient severity, general dysfunctioning in terms of OCB, tics, and associated mood/anxiety disorders (Black and Gaffney 2008). When it comes to research, it was argued that, without uniformity of selection criteria, crossstudy comparisons are impossible (Apter et al. 1996). In order to achieve this uniformity a useful diagnostic means which enables clinicians to diagnose individuals with subclinical OCD as well as clinical OCD is essential. Especially individuals at risk for OCD could benefit from an early detection, since the presence of subclinical OCD may herald the onset of OCD (Black and Gaffney 2008).

\subsubsection{Prevalence of OCD and OCB}

As mentioned before symptom-continuity can result in different diagnostic criteria. This may explain why until the 1980's OCD was thought to be a rare condition. Authors like Rasmussen and Eisen quoted an extremely low prevalence rate of $0.05 \%$ of the general population (Rasmussen and Eisen 1990), whereas Degonda et al. later doubted this attribution (Degonda et al. 1993). Already in the mid 1980s the Epidemiological Catchment Area study suggested prevalence rates for OCD of $2 \%$ to $3 \%$ in the United States (Karno et al. 1988). These findings were later replicated in crossnational, cross-cultural surveys from various DSM-III studies in seven countries. Lifetime 
prevalence rates ranged from $0.7 \%$ to $2.5 \%$ (Weissman et al. 1994). In 1990 OCD was described as the fourth most common psychiatric disorder in the general population (Rasmussen and Eisen 1990). Sasson et al. estimated that the worldwide prevalence of OCD is $2 \%$ in the general population and consequently accentuated the necessity of specific screening for OCD (Sasson et al. 1997). Stein et al. and Crino et al. doubted the validity of epidemiological data based on the DSMIII OCD (Stein et al. 1997, Crino et al. 2005), which was mainly assessed by the Diagnostic Interview Schedule (DIS). Crino et al. re-examined the prevalence rate of DSM-IV OCD and found lower percentages. The twelve month prevalence in Australia was $0.6 \%$. The authors explained the differing prevalence rates as a function of the changes in diagnostic criteria from DSM-III to DSMIV (Crino et al. 2005). These findings demonstrate the dependence of prevalence rates on definition and the applied type of interview. Different prevalence rates in so called unlike countries (Weissman et al. 1994) suggest also a cultural dependence. In a comparison of 13 epidemiological studies of young people aged 7-18, prevalence rates of 0.1-0.4\% were quoted (Heyman et al. 2001). Few of these studies included prepubertal children (Heyman et al. 2001). The prevalence of OCD in younger children is relatively unstudied. In a nationwide British survey 10438 children, within the age range of 5-15, were assessed to establish the prevalence of OCD. An overall prevalence of $0.25 \%$ was found. Dividing the sample in four different age groups, an exponential increase in the rate of OCD with age was indicated (Heyman et al. 2001). The increase of prevalence rates was also stated by Carter et al. reporting $1 \%$ in prepubertal children and $4 \%$ in adolescents (Carter and Pollock 2000). Hudziak et al. quoted lifetime rates of OCD in adolescents of 1.9\%-4.1\% (Hudziak et al. 2004). The higher prevalence rates nowadays could be due to an increase of incidence, the improvement of screening instruments or an increased awareness and information available on the disease (Wewetzer et al. 2007). In addition there might also be children who are misdiagnosed or undiagnosed (Heyman et al. 2001). It was supposed that patients have not been diagnosed because of subclinical symptoms (Thomsen 1995), which were thought to be a primary stage of OCD (Flament et al. 1988).

In contrast Maina et al. figured that obsessive and/or compulsive behavior which failed to meet one of the severity criteria of impairment, represent a normal phenomenon in older adolescents. In their sample of 1,883 they found a prevalence of $12.3 \%$ (Maina et al. 1999). The prevalence rates found in other studies were as follows: lifetime prevalence at $2 \%$ in a study of adults (Grabe et al. 2001); $2.7 \%$ in a Polish study of adolescents (Brynska and Wolanczyk 2005); prevalence at $43.1 \%$ of OCB in Egyptian students (Okasha et al. 2001); and 19\% of children experiencing subclinical symptoms (Valleni-Basile et al. 1994). This broad range in prevalence rates of OCB can be explained by different definitions, varied screening tools or diverse cultures. 


\subsubsection{Time of onset, gender-related aspects and course of OCD and OCB}

Rasmussen and Eisen compared several studies and found an average age of OCD onset in late adolescence or early adulthood, with males having an earlier onset than females (Rasmussen and Eisen 1990). March and Leonard reported a prepubertal onset of OCD in boys and a start of symptoms in girls during adolescence (March and Leonard 1996). Some studies did not agree with this gender discrepancy concerning the age of onset (Hanna 1995, Honjo et al. 1989). Crino et al. reported an average age at onset of 26.1 years (Crino et al. 2005), the mean age at onset of patients seen at the National Institute of Mental Health was 10.2 years (March and Leonard 1996). Another study found the mean age at onset with 10.0 years (Hanna 1995).

In the DSM-IV-TR it is written that OCD is chronic for most affected persons (AmericanPsychiatric-Association 2000). However, a comparison of 22 follow-up studies and 16 samples found a mean persistence rate for OCD of only $41 \%$. Poor prognostic factors were early age of OCD onset, inpatient status, and deficient initial treatment response and comorbid psychiatric illness. Other researchers have failed to identify any influence on prognosis of the age of OCD onset (Thomsen 1994, Allsopp and Verduyn 1989). Gender differences were not found as predictors of the further course (Stewart et al. 2004). The male-to-female ratio among affected children is about 2:1 (Hanna 1995, Toro et al. 1992). However, from adolescence onward, there is no difference between the sexes in the prevalence of OCD (Walitza et al. 2011). According to Wewetzer et al. half of the patients show either a chronic or an episodic course of OCD. They found a high prevalence of comorbid psychiatric disorders in the long-term follow-up (Wewetzer et al. 2001). Walitza et al. reported that $70 \%$ of OCD patients suffer from comorbid mental disturbances (Walitza et al. 2011). Children and adolescents with OCD are known to have multiple obsessions and compulsions which change in form and severity over time (Hanna 1995). A sample of 5 to 15years-olds showed equal rates of OCD in boys and girls (Heyman et al. 2001).

In a longitudinal assessment covering 11 years a lifetime prevalence rate for OCB at age 30 was $5.5 \%$, the rates being highest at the age of 20 and tending to decrease over time (Degonda et al. 1993). Degonda et al. found that the mean age of onset for OCB was 17 for males and 19 years for females. $70 \%$ of these affected individuals had an age at onset of symptoms before 20 years. A sex difference in prevalence of OCB was not found (Degonda et al. 1993). An association between poor course of OCB and coexisting tics in childhood was described previously (Leonard et al. 1993). 


\subsubsection{Assessment of pediatric OCD/OCB}

\subsubsection{How to screen for OCD}

Recent data showing high prevalence, the severity of OCD and the amount of undiagnosed or misdiagnosed children (Heyman et al. 2001) resulted in increased attention of researchers and clinicians for the assessment and treatment of this disorder. Ever since, several measures and instruments have been developed in order to assess OCD in children of the community or in clinical settings. Each has its strengths and weaknesses. According to Merlo et al. most of them do not seem to adequately account for patients who present with various mild symptoms or those who suffer from one or two symptoms that cause massive impairment. Reviewing the existing measures they concluded stating the need of further research in order to improve diagnostic capabilities and sensitivity to treatment effects (Merlo et al. 2005). The need to create a satisfactory screening tool for $\mathrm{OCB} / \mathrm{OCD}$, because of weaknesses of the existing ones, had been mentioned by Nelson et al. and Storch et al. (Nelson et al. 2001, Storch et al. 2006). A common measure to record OCD symptoms is the Children's Yale-Brown Obsessive-Compulsive Scale (CY-BOCS). Still it is designed to be administered only by clinicians and therefore it is not useful for screening (Geller et al. 2006). Others, like the Leyton Obsessional Inventory-Child Version, have not achieved widespread utilization for different reasons (Geller et al. 2006). The difficulties in diagnosing OCD cannot be underestimated as particularly subclinical symptoms are high (Muris et al. 1997). As a result, OCD in childhood is often diagnosed a long time after symptom onset (Calvocoressi et al. 1995). Its secretive nature adds to the frequent under-recognition (Geller et al. 2006). The underdiagnosis of OCD is supposed to be mainly caused by missing training and inexperience of pediatricians and family doctors (Hudziak et al. 2006). A widely available screening instrument with an easy administration that at the same time has to be accurate and efficient in early detection is needed (Hudziak et al. 2006). The latter is even more crucial, because effective treatment is available (Döpfner and Rothenberger 2007), and early detection and treatment of childhood OCD can improve clinical outcome (Pelchat 2002, Mathews et al. 2004). Furthermore "the cost of identifying an individual falsely [...] should not be so great as to outweigh the benefits of early detection of a person with the disease" (Hudziak et al. 2006, p. 164). In this case the cost of identifying somebody falsely would lead to further examination of psychopathology. The resulting cost does not prevail over the possible benefits. 


\subsubsection{Evaluation of screening tools}

Moll et al. (2000) studied the presence of OCB in children with ADHD and chronic tic disorders (CTD)/Tourette syndrome (TS). Three different instruments were used for screening: the Leyton Obsessional Inventory-Child Version (LOI-CV), the Mannheim Parent Interview and a measure of OCB. The latter consists of nine items derived from the Child Behavior Checklist (CBCL), which are supposed to be related to OCB (obsessions (item 9); fears own impulses (31); needs to be perfect (32); compulsions (66); sleeps little (76); stores up unneeded things (83); strange behavior (84), strange ideas (85); and too concerned with neatness or cleanliness (99)). None of the three instruments by itself was able to diagnose OCD. The LOI-CV appeared to be the only appropriate method to record obsessions, since the other tools are based on parent reports, and therefore only focus on observable compulsive behavior (Moll et al. 2000). Still, the use of the LOI-CV is limited, due to its lack of applicability other than for OCD and its insufficient positive predictive value (PPV) of 15\%-18\%. On the other hand its sensitivity and specificity (75-88\% and 77\%-84\%) were found to be reasonable. It was also criticized that several diagnostic instruments for OCD require too much time and/or have to be performed by expert clinicians (Nelson et al. 2001).

\subsubsection{The creation of an OCD subscale}

Reflecting existing measures, Nelson et al. (2001) saw the need for a screening tool for OCD with a high applicability. They utilized items of the CBCL, as it is a widely used instrument in child and adolescent psychiatry and it is easy for parents to understand and to complete (Nelson et al. 2001). Furthermore the reliability, validity, and temporal stability of the scales had been proven previously (Achenbach et al. 1991). Nelson et al. analyzed eleven items that were hypothesized to be the most adequate to the diagnosis of OCD. Because of small item loading values, three items were removed. The final obsessive-compulsive disorder subscale of the CBCL (CBCL-OCS) consisted of the following eight items, which have shown good internal consistency (Cronbach's alpha=.84): repeats certain acts over and over, compulsions (item 66); feels too guilty (52); worries (112); strange behavior (84); can't get his/her mind off certain thoughts, obsessions (9); feels he/she might think or do something bad (31); strange ideas (85); feels he/she has to be perfect (32). Since the answering scale is three optional $(0,1,2)$, the possible scoring of the CBCL-OCS ranges from 0 to 16. In their study, Nelson et al. compared three samples of equal size of children and adolescents, who were matched for gender and age. They were composed of diagnosed (DSM-IV) OCD patients, a psychiatrically treated group without evidence of OCD and a control group from the general 
population. The CBCL-OCS discriminated between the three groups. The OCD group showed significantly higher scores on the CBCL-OCS than the other two samples. Their CBCL-OCS demonstrated high levels of sensitivity, specificity and high diagnostic power. Nelson et al. assumed a favorable performance compared to the LOI-CV. As further advantage of the CBCLOCS the authors mentioned its frequent use in many studies in 56 countries (Nelson et al. 2001). The prevalence could be evaluated retrospectively using the collected data of the CBCL. Furthermore its utility to identify other problems than OCD had been established and computer scoring algorithms are available. Hudziak et al. highlighted the availability in 69 languages and the well-established relationship with DSM-IV childhood onset diagnoses as another advantage (Hudziak et al. 2006). As a limitation of their study, Nelson et al. noted the use of the same data for the development and evaluation of the CBCL-OCS. Besides, the number of each sample appeared small $(n=73)$ and the selection of both the clinical controls and the OCD group resulted from a highly comorbid population. They recommended the examination of the CBCL-OCS performance in samples of different composition to clarify completely its general usefulness, pointing out the importance of making a punctual diagnosis of OCD in children and adolescents (Nelson et al. 2001).

\subsubsection{Evaluation of the CBCL-OCS}

Hudziak et al. (2004) evaluated genetic and environmental influences, sex differences and sibling interaction/rater contrast effects on the CBCL-OCS. They used a large cross-cultural twin study from the Netherlands Twin Registry and the Missouri Twin Study. Genetic influences and unique environmental influences on the CBCL-OCS were present at 7 and 10 years of age, with common environmental influences only at 12 years of age. The latter was explained by the presence of autoimmune processes. They found little to no differences in the heritability of symptoms measured by the CBCL-OCS between females and males. Neither sibling interaction nor rater contrast seemed to affect the results. The similarity across sex and age supported the suggestion that deviance on the CBCL-OCS represents a stable syndrome. The strong genetic influences of OCD shown in this study could also be a reason for its general under-recognition, as children may not be identified, because their parents have similar symptoms. Hudziak et al. used the CBCL-OCS in different samples to examine the usefulness of these item scores for the detection of OCD (Hudziak et al. 2006). First they applied a receiver operating characteristic curve analysis (ROC) to the data, previously described by Nelson et al. (2001), in order to establish the best sum score on the CBCLOCS to predict OCD in children. Secondly they applied a determined cut-off (cut point of 5, 
sensitivity $=91.8 \%$, specificity $=67.2 \%$ ) to a sample of CBCL data from 2460 children and to 20016 children from three general population twin samples. The data was sorted in one group of youth meeting criteria for DSM-IV OCD, one group of clinical controls and a group of general population non-clinical controls. The CBCL-OCS scores of the OCD group were higher than those of the clinical controls, which were also elevated compared to the score of general population controls. Their findings suggested that the CBCL-OCS may offer a very effective way to screen for childhood OCD in general pediatric populations as well as for research means. As a disadvantage they also mentioned the size and composition of the sample previously described by Nelson et al. (2001), on which the CBCL-OCS was tested. The patients with OCD and the clinical controls were selected from a highly comorbid population, without controlling for those effects. Some participants were suffering from ADHD, affective and other anxiety disorders (Nelson et al. 2001).

Additional evaluation was performed by Geller et al. (2006), using the CBCL-OCS by Nelson et al. (2001) to investigate its usefulness in a separate cohort. They also wanted to create a simplified scale of OCD using a nonparametric recursive partitioning method. The participants were youth drawn from three different studies. They used a sample of youth meeting criteria for DSM-IV OCD $(\mathrm{N}=64)$, psychiatric $(\mathrm{N}=64)$ and healthy controls $(\mathrm{N}=65)$. The psychometric properties like sensitivity, specificity, negative predictive value (NPV), PPV as well as CBCL-OCS scores were very similar to those found by Nelson et al. (2001). Such consistent results support the use of the CBCL-OCS as a screening instrument to diagnose OCD in youth. However, Geller et al. (2006) also mentioned limitations of the method. They criticized that the result of a 3-level ordinal scale items rating is used for factor analysis, because it evaluates data as if it were continuous. They noted that an item score of "often true" $(=2)$ may not justify a twofold contribution to the OCS score compared to an answer of "sometimes true" $(=1)$. Moreover, they criticized that the calculations needed to create an OCS score are complex and not readily retrievable to the practicing clinician. On the other hand, accepted factor loadings from two other studies could be applied (Nelson et al. 2001, Hudziak et al. 2006). Modifying CBCL-OCS, they applicated the classification and regression trees (CART) method. This technique uses binary recursive partitioning to select the CBCL items which are best in predicting OCD. In the study they used only 3 raw CBCL item scores: obsessions (item 9), compulsions (66) and worries (112). The method predicted that parents of OCD youth will reply "always true" or "somewhat true" for CBCL item 9 AND either CBCL item 66 or CBCL item 112 with a sensitivity of $86 \%$, a specificity of $91 \%$, a PPV of $83 \%$ and a NPV of 93\%. Concluding, it was classified by Geller et al. (2006) as an appealing alternative to the CBCL-OCS by Nelson et al. (2001). Another study re-examined the psychometric properties of the CBCL-OCS. Merlo et al. underlined the use of parent-rating as strengths of this tool, since 
underreporting is commonly characteristic in ego-syntonic OCD. As specific strengths of the CBCL the ease of administration and scoring, the high distribution and the existence of parallel self- and teacher-report were mentioned (Merlo et al. 2005).

Storch et al. (2006) saw a reason for further evaluation in the fact that the CBCL-OCS item content was based on results from a principal factor analysis where factors with so called "Eigen values" $>1$ were extracted. The use of this criterion alone to extract factors is susceptible to retaining too many factors. Their sample consisted of 190 children and adolescents with the mean age of 10.5 years. One group included 48 subjects with a primary diagnosis of OCD. The participants of the second group were diagnosed with internalizing disorders other than OCD. The third group included 101 subjects with externalizing disorders. As measurements of obsessions and compulsions, besides the CBCL, they used the CY-BOCS and the Tourette's Disorder Scale. The utility of both are limited, because they focus only on a few possible symptoms of pediatric OCD. The scale developed by Nelson et al. (2001) in contrast is assumed to assess shared phenomenological elements across varied pediatric OCD clinical presentations. A confirmatory factor analysis (CFA) was performed and resulted in a relatively poor fit in their sample. The inferior mean age of the participants, the smaller sample size or differences in regard to demographics and illness presentation (e.g., comorbidity) were held responsible for this. Subsequently they performed an exploratory factor analysis (Stefanoff et al. 2007), which also suggested a similar 1-factor model. Items 32 (feels he/she has to be perfect) and 84 (strange behaviors) were dropped from the scale. Therefore their revised version of the CBCL-OCS involves six items of the former CBCL-OCS: Obsessions (item 9); fears own impulses (31); feels too guilty (52); compulsions (66); strange ideas (85) and worries (112). It was also able to discriminate between youths with OCD and those suffering from internalizing or externalizing disorder. The revised version correlated strongly with the CBCLOCS, which could mean that the new version is able to provide the same amount of information as the old one. Their relatively higher relationship with measures of OCD suggests that the new one may provide a more efficient symptom measurement, although sensitivity and specificity were not consistently high for any cut-off value and lower than those of Nelson et al. (2001). Still it should not be used as the only screening instrument. Furthermore, many children may hide their symptoms with the consequence of unawareness by their parents and different results in the CBCL. On the basis of their results, the revised CBCL-OCS seems to be a valid and reliable instrument for the assessment of pediatric OCD, but additional studies are needed to re-examine their results (Storch et al. 2006).

The aim of a study published in 2008 by Ivarsson and Larsson was to extend and further validate outcomes of prior studies of the CBCL-OCS in a different population. They also wanted to examine 
whether the previously used CBCL-OCS scores are optimal or if other constellations would perform better. They compared an OCD group (children referred to a specialized child psychiatric OCD clinic) and a sample recruited from regular child and adolescent psychiatric outpatient clinics (CPO group). Both groups were compared to a normative school sample (SS group). In their results ten CBCL items could distinguish children with OCD from CPO patients. After further analyses they concluded that the two CBCL items obsessions and compulsions were the strongest predictors. They performed well because screens and the addition of other CBCL items did not further increase sensitivity or specificity. Concluding, the authors recommended that parental responses on these two items should be used as screen for OCD in children and adolescents in regular child psychiatric clinics. They noted that the two items together with the other six in the Nelson CBCL-OCS should work well as a screen for OCD in children and adolescents (Ivarsson and Larsson 2008). The latest study concerning the OCS scores was published in 2009. Althoff et al. (2009) used the latent class analysis (LCA) of the CBCL-OCS to identify profiles within this 8-item scale and to examine heritability of those profiles. The LCA was performed on maternal CBCL reports of their children and adolescents from Dutch twins in the Netherland Twin Registry at ages 7, 10 and 12 and from two US nationally representative samples. A solution with four classes fitted all samples best ("No or Few Symptoms", "Worries and Has to Be Perfect", "Thought Problems", "High Levels of All Items"). They concluded that LCA identifies the membership of one class. The study also supported the heritability of the classes and approved the usefulness of the CBCL-OCS (Althoff et al. 2009).

\subsection{Tic disorders}

\subsubsection{Definition and classification}

A tic is an involuntary, recurrent, sudden, and purposeless motor movement or vocalization of brief duration, which occurs at irregular intervals (Shapiro and Shapiro 1981). Generally tics begin in proximal areas of the body. Over time they can fluctuate in location, pattern, intensity, frequency and complexity. Tics may increase during emotional activity (e.g. happiness, anger, stress) or by the use of stimulants and decrease by concentrated work, consume of either cannabis or alcohol or relaxation in a supine position (Rothenberger and Banaschewski 2006). Tics can also be seen during sleep in a diminished intensity and frequency (Fish et al. 1991). It is possible to suppress them for a little while, but suppression can be associated with an increase of inner tension leading to a more forceful tic afterwards (Rampello et al. 2006). Although functional interference due to tics is relatively rare (Gilbert 2006), homework or falling asleep can be prolonged by bouts of tics (Roessner et al. 2011). Recurrent phonic tics can impair fluency of speech (Roessner et al. 2011). 
The diagnoses of tic disorders (TD) are based on observation and careful history taking, since there does not exist a diagnostic laboratory test (Khalifa 2006). Tics can be divided into motor and phonic ones. Each of these can be further separated into simple and complex types. Simple phonic tics are inarticulate noises such as coughing, sniffing, throat clearing sounds, grunting or tongue clicking. Examples of complex phonic tics contain the repetition of involuntary words or phrases, echolalia (repeating the speech of another person), palilalia (repeating the words of one's own) or coprolalia (usage of obscene speech). Simple motor tics include an eye blink, head jerk, facial grimace, and shoulder shrug. Complex motor tics are similar to normal acts that are inadequate, but appear purposeful (Kuperman 2002). Examples are hopping, squatting, touching objects or other people, self-injurious behavior, copropraxia (obscene gestures), and echopraxia (imitation of other people's movements). TD probably represent a continuum from the transient form beyond the CTD through TS. According to the DSM, TD are further divided into a transient/chronic motor or vocal form and TS (American-Psychiatric-Association 1994). The latter has to be present for more than twelve months without a tic-free period of more than three following months and the transient form persisting at least four weeks and no longer than twelve sequent months. The transient form is the most common and mildest form (Khalifa 2006). The most severe TD is the TS, which is named after the French neurologist Gilles de la Tourette. It is defined as the presence of multiple motor tics and one or more vocal tics appearing simultaneously or at different periods during the illness. They occur throughout a period of more than a year with no tic-free period for more than three consecutive months. The tics first occurred before age 18 and they cause marked distress. By late childhood many TD patients recognize a premonitory sensation preceding a tic (Banaschewski et al. 2003). The premonitory urges consist in focal tension or pressure in body parts related to the tic or in a diffuse inner tension or anxiety (Banaschewski et al. 2003). They are described as more bothersome than the tics (Cohen and Leckman 1992) and it has been reported that after completing the tic a sensation of temporary relief seems to emerge (Leckman 2002).

\subsubsection{Prevalence and course}

The prevalence of TD is very variable depending on the methodology and sample used. Transient tics occur frequently in children at the age of 3-10 years (Rampello et al. 2006). Simple tics are observed earlier than complex ones (Rampello et al. 2006). Prevalence rates were reported as follows: $2.6 \%$ for transient tic disorders according to ICD-10 (Stefanoff et al. 2007), 5.1\% according to DSM-III-R (Nomoto and Machiyama 1990). Döpfner et al. estimated a prevalence of $4-12 \%$ of transient tics in children of elementary school age (Döpfner et al. 2010). Moll and 
Rothenberger reported a prevalence rate of 8-10\% (Moll and Rothenberger 1999). Others indicated a prevalence rate of CTD of about 3-4\% (Rothenberger and Banaschewski 2006, Stefanoff et al. 2007). The prevalence of TS varies within a range of 0.05-3\% (Moll and Rothenberger 1999, Karno et al. 1988). Simple motor tics have been observed in children aged 5-10 years, while vocal tics are described later (8-15 years) (Rampello et al. 2006). Leckman found the onset of motor tics within the age range of 3 to 8 years and the later onset of phonic tics was confirmed (Leckman 2003). During a day motor and phonic tics occur in bouts and over the course of weeks to months they wax and wane in severity (Peterson and Leckman 1998). The period of greatest fluctuations in tic severity was observed in children of 10 to 12 years of age (Leckman 2003). After adolescence there is a tendency of spontaneous remission of tics (Rothenberger and Banaschewski 2006). The age of onset of TS is usually before seven years (Rampello et al. 2006). The severity of symptoms may wax and wane, with peaks of severity found at the age of 9-11 years (Singer 2000). In evaluating treatment, it is important to be aware of the natural waxing and waning of tics in TS (Roessner et al. 2011). The reported frequency in children and adolescents is higher than in adults, showing the tendency of spontaneous remission of symptoms after adolescence (Rothenberger and Banaschewski 2006). Follow-up studies suggested that one-third of children with TS will be free of symptoms as adults, while another third will remain with mild symptomatology and 10-30\% suffer chronically (Rothenberger and Banaschewski 2006). A study by Pappert et al. used video analyses to confirm the persistance of tics in adult TS patients. In $90 \%$ of cases, tics were still observable, although the patients were not always acutely aware of them (Pappert et al. 2003). Coffey et al. found a decrease in impairment as time went on, even if tics persisted (Coffey et al. 2004). In addition the long-term outcome of individuals is influenced by comorbid diseases such as ADHD or OCD (Leckman 2003). Tic severity during childhood did not turn out to be a prognostic factor for the further course of TD (Kuperman 2002). The male-to-female ratio for TD is 3-4.5/1 (Rothenberger and Banaschewski 2006), whereas in TS and chronic motor TD an estimate of 5/1 exists (Rampello et al. 2006). Gender differences are also found concerning combordities. Male patients are more affected by coexisting externalizing problems, while female TD patients suffer more often from coexisting OCB (Döpfner et al. 2010).

\subsection{Attention-Deficit-Hyperactivity Disorder}

\subsubsection{Definition and classification}

The diagnostic criteria are defined in the ICD-10 (World Health Organisation 1996) and in the DSM-IV (American-Psychiatric-Association 1994). The World Health Organization published 
Diagnostic Criteria for Research for mental and behavioral disorders for the ICD-10, including hyperkinetic disorder (HD), in 1993 (Lahey et al. 2006). One year later, the fourth edition of the DSM published revised diagnostic criteria for ADHD (Lahey et al. 2006). The DSM-IV category is wider and therefore a more common diagnosis than the ICD-10 diagnosis of HD (Taylor et al. 2004). According to the DSM-IV the main symptoms of ADHD are inattention and hyperactivityimpulsivity. The ICD-10 criteria require the presence of attention, hyperactivity and impulsiveness problems and the absence of a depression or an anxiety disorder (Taylor et al. 2004). According to the DSM-IV three subtypes of ADHD can be diagnosed: ADHD primarily of the inattentive type, ADHD primarily of the hyperactive-impulsive type and ADHD combined type. The most common one is the combined type (Hurtig et al. 2007), which is diagnosed when several behaviors of inattention and hyperactivity-impulsivity are met. Moreover, it is also considered to cause the greatest impairment (Hurtig et al. 2007). In order to meet the DSM-IV or ICD-10 criteria, symptoms have to be present for at least half a year. They have to be inadequate for the developmental status of the child, functional impairment must be reported in at least two settings (e. g. at home and at school), and the age of onset has to be inferior to seven years. Both diagnoses require that the symptoms cannot be explained by another psychiatric disorder (Steinhausen 2010a). Symptoms of inattention include: failing to pay close attention to detail or careless errors in schoolwork, or other activities namely seeming not to listen, disliking or avoiding tasks that require sustained attention, losing or forgetting things, easy distraction by extraneous stimuli, forgetfulness and failing to finish tasks. Hyperactivity is present when children are inappropriately running or climbing, unable to stay seated, having difficulty in playing quietly or engaging in leisure activity and talking excessively. Impulsivity can be seen in answering questions before they have been asked completely, having trouble awaiting one's turn and interrupting others.

\subsubsection{Prevalence and course}

The prevalence rate of ADHD varies, since it depends on many factors such as the constitution of the sample (community samples vs. school samples), the method of ascertainment (informants asked to assess symptoms; information obtained through questionnaire or from direct interviews), the applied diagnostic criteria, age and sex of children, the region where the study has been conducted, and comorbidity. The prevalence of ADHD was estimated as a variation between 1,7\% and $17,8 \%$ (Elia et al. 1999). Other studies quoted prevalence rates of at least $4 \%$ to $7 \%$ (Gillberg et al. 2004), 3\% to 5\% (Arnold et al. 2005) or suggested a worldwide prevalence of $3 \%$ to $6 \%$ among the school-aged population (Goldman et al. 1998). When DSM-III-R criteria were applied in 
international studies, a prevalence of ADHD ranging from 3\% to $10 \%$ was found (Steinhausen 2010b). However, DSM-IV criteria include the inattentive type of ADHD, which may be partly responsible for the elevated prevalence rates of $7,4 \%$ in the USA. Since the DSM-IV category is wider, the prevalence rates of HD diagnosed with ICD-10 are considerably lower. Steinhausen quoted a mean worldwide prevalence of ADHD independent of diagnostic criteria of 5,3\% (Steinhausen 2010b). ADHD occurs significantly more frequently in boys than in girls (Faraone et al. 2003). One study estimated a male to female ratio of at least 4 to 1 (Gaub and Carlson 1997). According to Steinhausen, the prevalence among pre-adolescent male children is 2 to 4 times higher than among females (Steinhausen 2010b). Cohen P et al. found a decrease of prevalence with increasing age (Cohen $\mathrm{P}$ et al. 1993). It was quoted that approximately $80 \%$ of children with ADHD still have symptoms in late adolescence and even in young adulthood (Faraone et al. 2003), but symptoms generally diminish with advancing age (Faraone et al. 2006). Hyperactivity is likely to decline at a younger age and at a higher rate than symptoms of inattention (Hurtig et al. 2007).

\subsection{Comorbidities}

\subsubsection{Coexisting OCD in children and adolescents with ADHD}

Coexistence, the manifestation of two or more diseases in one person, is very common in child and adolescent psychiatry (Caron and Rutter 1991). A symptom can be caused by different disorders or the interaction of various disorders.

As mentioned above ADHD is a very frequent disorder in childhood. It has been reported that in the majority of cases it is associated with at least one other major psychiatric problem/disorder and that the coexistence of other disorders might be at least as important as ADHD for the long term outcome in the individual child (Gillberg et al. 2004). Peterson et al. found an increased risk only for the development of OCD in older adolescents and adults affected by ADHD, but not in prepubertal children of a community sample with ADHD (Peterson et al. 2001). The frequent coexistence of other disorders has important clinical implications since the exact identification of each syndrome could lead to a more adequate treatment. In conclusion, a treatment of each disorder is required for children who suffer from ADHD as well as from OCD (Geller et al. 2002). Whereas stimulants are the most common medication for children and adolescents with ADHD, they seem to have no therapeutic effect on OCD (Geller et al. 2002). In rare cases stimulants can even cause obsessions or compulsions (Kouris 1998, Kotsopoulos and Spivak 2001). OCD is often treated with serotonin reuptake inhibitors (Geller et al. 1995), which are not effective in the treatment of ADHD. In contrast they are known to cause behavioral activation in some children (Geller et al. 1995). But 
the coexistence of ADHD in children with OCD is not only relevant for the pharmacological treatment. The core symptoms of ADHD can adversely affect the participation of children in psychosocial treatment of OCD (Geller et al. 2002). There are few studies dealing with the coexistence of ADHD and OCD, although prevalence rates of co-occurring ADHD in children and adolescents with OCD of $6 \%$ to $15 \%$ have been reported (Gillberg et al. 2004). Other studies of children with OCD quoted prevalence rates of ADHD, varying from 9\% to 33\% (Swedo et al. 1989, Geller et al. 1996, Leonard et al. 1993, Hanna 1995, Reddy et al. 2000). The results of Geller et al. supported a true comorbid state of OCD plus ADHD when ADHD-like symptoms are seen in youth with OCD. They figured that the symptoms of inattention and distractibility often seen in children with OCD could either be ADHD-like symptomatology secondary to OCD or represent a true cooccurrence of ADHD (Geller et al. 2002). In the majority of children affected with both disorders, the onset of ADHD preceded the development of OCD by several years. Geller et al. measured a significantly higher impairment of global psychosocial functioning in the comorbid ADHD+OCD group than in the ADHD-only group with the Global Assessment of Functioning score (Geller et al. 2002). These results support the idea that children with ADHD plus OCD are devastated with the full psychosocial burden of both disorders. In their subsequent study Geller et al. examined the impact of coexisting ADHD on the phenotypic expression of pediatric OCD (Geller et al. 2003). Children suffering from both disorders had higher rates of special class placement, needing extra help in class, somatic obsessions and panic disorders than children who were affected by OCDonly. Sukhodolsky et al. (2005) compared children and adolescents of four different groups: OCDonly, OCD+ADHD, ADHD-only and unaffected comparison children. Children with OCD+ADHD had lower scores in social and school competencies in the CBCL than children with OCD-only. The $\mathrm{OCD}+\mathrm{ADHD}$ group also showed more impairment on the internalizing problems scale of the CBCL compared with all other groups. As a result, data of this study suggested additive contribution of OCD and ADHD to social disability (Sukhodolsky et al. 2005).

\subsubsection{Coexisting OCB in children and adolescents with ADHD}

Arnold et al. (2005) examined OCB in a clinical sample of children with ADHD. They identified clinically significant $\mathrm{OCB}$ in $11.2 \%$ of children with ADHD. In children having both ADHD and OCB they found an increased impairment compared to children with ADHD-only. Arnold et al. (2005) accentuated the importance of knowledge about the clinical features of this particular coexisting condition and the need to arrange comprehensive clinical assessments; according to parent ratings the children with $\mathrm{ADHD}+\mathrm{OCB}$ had significantly more impairment than the ADHD- 
only group. In the domains of perfectionism, cognition/inattention and family history, significant differences were found between the two groups (ADHD vs. ADHD+OCB). The children with the diagnosis of $\mathrm{ADHD}+\mathrm{OCB}$ showed increased rates of perfectionism, better teacher ratings of inattention/cognitive problems, and a lower probability of having a first-degree relative with ADHD than the group of children with ADHD-only. The two groups were similar on most behavioral characteristics, IQ, academic function, expressive and receptive language abilities, and neurobiological and psychosocial risk (Arnold et al. 2005).

As Moll et al. (2000) assumed the existence of an age-dependent behavioral continuum of OCB to OCD; they studied the existence of OCB in children with ADHD and CTD. Contrary to the expected order, self-reports of children with ADHD showed significantly higher OCB scores in the LOI-CV than those of children with CTD. Especially on the item subsets regarding contamination fears, repetition, over conscientiousness and hoarding ADHD-related OCB could be seen. The authors suggested that repetition, over conscientiousness and hoarding might be related to a decreased behavioral flexibility. Interestingly, children with CTD did not obtain significantly higher scores on the CBCL-OCS than children with ADHD. They stated that the externalizing symptoms seen in children with ADHD might mask their OCB. As a conclusion Moll et al. mentioned the need of thorough investigation and monitoring for OCB in children with CTD as well as in young patients with ADHD (Moll et al. 2000).

\subsubsection{OCD and TD}

Phenomenologically compulsions and complex motor tics can appear very similar and therefore it can sometimes be impossible to differentiate them by the symptoms. But the non visible intentions are different. Compulsions serve to reduce anxiety, distress or tension, whereas complex tics are due to different kind of premonitory sensory phenomena. These sensations are experienced as an urge for motor discharge. The inner sensory urge can also result from the completion of a tic and then lead to the repetition of the tic until it feels "just right". Compulsions result from obsessions or follow strict rules. A conversion into a motor activity can lead in both disorders to a short relief. Moll et al. assumed the existence of a continuum of symptoms ranging from single tics to a mixed picture of tics/rituals/obsessive-compulsive traits to clinically relevant obsessions and compulsions (Moll et al. 2000). Tics and obsessions/compulsions have a lot in common, the characteristics being: involuntary, repetitive, senseless, leading to the reduction of anxiety, causing resistance and anticipations. If there is a mixed picture of symptoms the treatment has to include interventions for both disorders in order to achieve extensive improvement. Furthermore it is important to know 
which disorder mainly contributes to the symptomatology in order to choose the right psychopharmacological agents (Moll and Rothenberger 1999).

Patients with TD show a wide range of social, emotional and behavioral problems. Often these problems are more disabling than the core tic symptoms, thus forming a major challenge to treatment (Hoekstra et al. 2004). Freeman suggested that up to $90 \%$ of CTD patients in clinical samples suffer from comorbidities (Freeman 2007). A complicating factor, arising out of a study by Leckman, is that comorbidities of TS change with age (Leckman 2002). In patients with comorbidity, the onset of TD normally precedes the symptoms of OCD (Döpfner et al. 2010). In many studies associations between OCD or OCB and TD have been reported. But the obsessions and compulsions differ in their phenomenology between tic-related and non-tic-related OCD (Holzer et al. 1994, Eapen et al. 1997). Therefore several studies compared patients with OCD with and without CTD or TS in regard to the content of their obsessions and compulsions (Holzer et al. 1994, Leckman et al. 1994, George et al. 1993). Roessner et al. concentrated on TD with or without OCB/OCD (Roessner et al. 2005), while others approached the overlap between OCD and TD by subtyping both disorders (Leckman et al. 2003). Generally, it is important to disentangle the overlap between the disorders and to find out the most distressing symptom(s) in order to offer a patient the appropriate treatment for effective symptom reduction.

Epidemiological similarities directed the focus of research to the genetic relation between OCD and TS. This idea was supported by increased rates of tics in OCD patients and their relatives (Leonard et al. 1992) and augmented rates of OCD in TD patients and their relatives (Pauls et al. 1991). Reported prevalence of OCD in CTD patients varies between 20-60\% (Lewin et al. 2010). Freeman et al. found a co-occurrence of OCD in TS patients in $27 \%$, while $32 \%$ were affected by OCB (Freeman et al. 2000). Elsewhere 18\% of TS patients suffered from comorbid OCB (Wang and Kuo 2003). Cardona et al. found a prevalence of OCB in 46\% of children with TD (Cardona et al. 2004). In a study by Termine et al. OCD was again the most common comorbid psychiatric disorder in children and adolescents with TS (Termine et al. 2006). Lewin et al. mentioned that 20-38\% of children with OCD are affected by comorbid tics (Lewin et al. 2010). Döpfner et al. quoted that 6$30 \%$ of OCD patients also suffer from TD (Döpfner et al. 2010). Tic-related OCD occurs more often in male individuals than in female persons (Zohar et al. 1997, George et al. 1993, Leckman et al. 1994).

Cardona et al. (2004) suggested that the comorbidity between tic and OCD could influence the development of emotional and behavioral difficulties. In their study patients with a pathological CY-BOCS score had an increased risk of having a pathological total score in the CBCL (Cardona et al. 2004). In contrast in another study, however, severity ratings and the means and standard 
deviations for scores on the CY-BOCS were not significantly different between the OCD groups with and without tics (Zohar et al. 1997).

\subsection{The triad of CTD, ADHD and OCD}

In order to offer a child the optimal treatment it is essential to be aware of all symptoms and problems in the individual patient and to know which disorder mainly contributes to his symptomatology (Moll and Rothenberger 1999). But if more complex psychopathological conditions are assumed an interactive model has to be considered. Peterson et al. studied the interrelatedness of tics, OCD and ADHD in a large sample of children, who were reassessed after 8, 10 and 15 years (Peterson et al. 2001). Tics and OCD were significantly associated with one another. Tics in childhood or early adolescence predicted an increase in OCD symptoms later in adolescence or in early adulthood. In this sample OCD and ADHD were also significantly associated with one another. ADHD in early adolescence predicted OCD in adulthood. The cooccurrence of tics and ADHD in late adolescence predicted more OCD symptoms in adulthood. The findings by Peterson et al. indicate that the co-occurrence of ADHD and tics in clinic patients could result in part from a complex sharing across development of numerous psychopathological risk factors like OCD (Peterson et al. 2001).

Banaschewski et al. also assumed a complex psychopathological pattern of tic, OCB, impulsivity and internalizing symptomatology, which requires discriminating assessment and treatment (Banaschewski et al. 2003).

In their recent study Pollak et al. (2009) examined the impacts of ADHD symptoms, tic severity, and OCD on internalizing and externalizing psychopathology in children and adolescents with TS. Therefore they used linear regressions. The CBCL scales of four different groups were also compared: TS-only, TS+ADHD, ADHD-only and an unaffected control group. The results suggested that tics, ADHD and OCD differentially explain the variance in externalizing and internalizing behavioral problems in individuals with TS. Still, their results are limited by several weaknesses: There were important differences in sample size and gender distribution among groups. Furthermore only results for the two wide-band scales (internalizing and externalizing problems) but not for the eight narrow-band subscales of the CBCL have been reported. Finally, patients were not systematically screened for other psychiatric disorders including learning disabilities (Pollak et al. 2009). 


\subsection{Aims of the study}

Until today there are only a few studies concerning the complex triad of CTD, ADHD and OCD. Studies on the triad of CTD, ADHD and OCD/OCB (Pollak et al. 2009, Peterson et al. 2001) raised the question if there was a main contribution of OCB to the psychopathology of our patient groups. The aim of the previous study by Roessner et al. (2007) was to further clarify and specify the contribution of CTD and/or ADHD to the broad psychopathological profile of the comorbid group $(\mathrm{CTD}+\mathrm{ADHD})$ in order to offer the affected children the best treatment possible. Consequently the psychopathological profiles of four large groups (CTD-only, ADHD-only, CTD+ADHD and controls) were measured by the eight subscales of the CBCL. The authors used a $2 \times 2$ factorial design with the factors CTD and ADHD. Contrasts were also calculated in order to specify the contribution of each factor to the psychopathology of the comorbid group in more detail than indicated by the main effects. At the level of psychopathology, an additive model for the cooccurrence of ADHD and CTD was supported (Roessner et al. 2007). The aim of our study was to investigate the possible contribution of OCB to a detailed psychopathology profile measured with the subscales of the CBCL in patients suffering from CTD and ADHD. Therefore we conducted the present study to extend the previous phenomenological studies concerning the overlap of psychopathology in children with CTD+OCB and ADHD+OCB.

The commonly used OCD rating scales like the CY-BOCS are primarily designed to screen for typical OCD populations (Cath et al. 2001). As to the investigation of OCB in CTD and/or ADHD subjects, who do not fulfill the diagnostic criteria of OCD, other measures are needed. Three subscales of the CBCL specific for OCB/OCD have already been used and evaluated by other authors (Moll et al. 2000, Nelson et al. 2001, Storch et al. 2006). Applying those instruments as covariates in analyses of covariance (ANCOVAs) we examined the effect of OCB on the psychopathology in CTD and/or ADHD subjects.

On the basis of previous findings we hypothesized that OCB has a main effect on the psychopathology of children with CTD. Beyond that confirmation we hypothesized that OCB symptoms also have an important effect-although to a lesser extent-on the psychopathology of children with ADHD. By applying the ANCOVAs to our sample we expected greater changes of psychopathology profiles in the group with CTD as a factor than in the group with ADHD as a factor. 


\section{Methods}

\subsection{Participants}

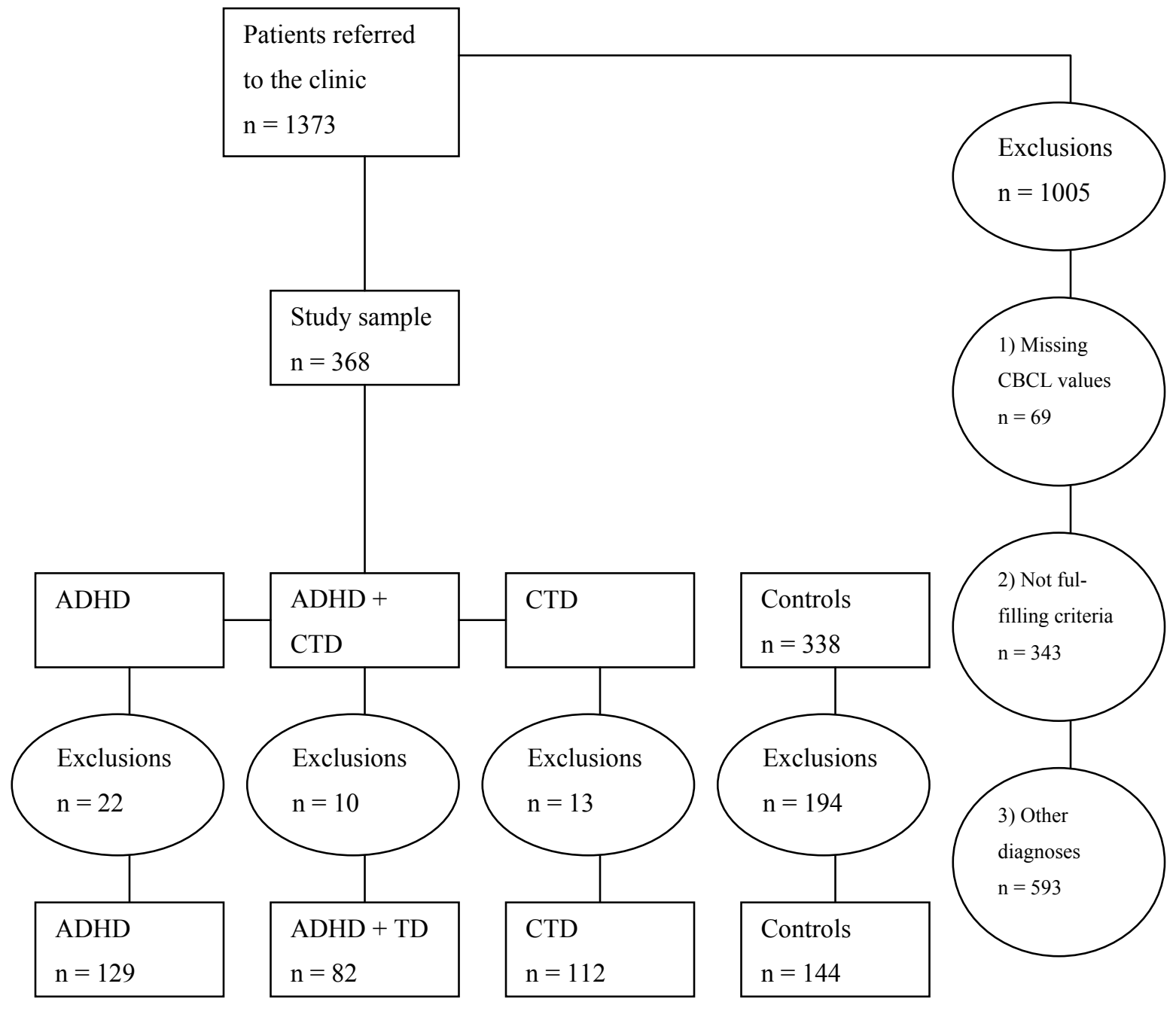

Figure 2.1: Flow chart of the study sample.

In our study we included children who were referred to the outpatient clinic of the Department of Child and Adolescent Psychiatry at the University of Goettingen for routine clinical assessment between January 1997 and January 2005. During this period a total number of 1373 patients were referred to the clinic. Three groups of patients were built: the first group consisted of children with merely ADHD and it is referred to as ADHD-only. The second group included children with coexisting $\mathrm{ADHD}$ and $\mathrm{CTD}$ and is further referred to as $\mathrm{ADHD}+\mathrm{CTD}$. A third group included children with CTD-only. 69 patients were excluded from the sample, as more than twenty values on their CBCL were missing. 343 children were not incorporated in the study, because they did not fulfill either CTD or ADHD diagnoses criteria. In order to reduce the influence of confounding variables of previous studies (age, sex, other psychiatric diagnoses than CTD and ADHD) further 
children had to be excluded to obtain results of high quality concerning the complex coexistence of CTD and ADHD. 593 children were excluded because of a secondary axis I psychiatric diagnosis besides CTD and ADHD (according to ICD-10 multiaxial classification system (World Health 1996)) or in order to evade differences in age or gender composition of the three groups. For the latter reason 13 children were excluded from the CTD-only group, 22 children of the ADHD-only and 10 children of the CTD+ADHD group. Finally patient group sizes and mean ages were: CTDonly $\mathrm{n}=112$, mean age $=11.1, \mathrm{SD}=2.6$ years; $\mathrm{CTD}+\mathrm{ADHD} \mathrm{n}=82$, mean age $=10.7, \mathrm{SD}=2.3$ years and ADHD-only $\mathrm{n}=129$, mean age $=10.5, \mathrm{SD}=2.5$ years. All the included children met the diagnostic criteria for CTD or TS alternatively hyperkinetic disorder according to ICD-10 (Dilling et al. 2000) and ADHD combined type just as CTD according to DSM-IV (American-Psychiatric-Association 1994). The patients did not show any other axis I psychiatric diagnosis. They were examined clinically and diagnosed on the basis of clinical observation, semi-structured interviews with parents and children (Englert et al. 1996) and different clinical ratings (e.g. Conners Rating Scale (Goyette et al. 1978); Tourette Syndrome Severity Scale (TSSS) (Walkup et al. 1992); Yale Global Tic Severity Scale (YGTSS) (Leckman et al. 1989). Subsequently the diagnoses were confirmed by senior board-certified child psychiatrists in case conferences. Subjects of the control group were selected from children referred to the outpatient clinic of the Department of Child and Adolescent Psychiatry at the University of Goettingen, who did not receive an axis I diagnosis according to ICD-10 multiaxial classification system (World Health Organisation 1996). They showed no or sub categorical problems or learning disorders (43\% learning disorder, 57\% were not diagnosed at all). Due to missing values in the CBCL 16 patients were excluded and 338 children remained in the control group. To create a group that did not differ statistically in age or gender from the three patient groups, 144 children were selected to form the control group. Their mean age was 10.4 and the standard deviation 2.4 years. Of all the participants of this study, more than $99 \%$ were Caucasians. The chart review was considered by the local Ethics Committee to be exempt from review, and written informed consent was not needed. The sample has been described earlier in a previous study by Roessner et al. (2007).

\subsection{Diagnostic measures: $C B C L$}

A parent of each child was asked to complete a CBCL questionnaire to measure different aspects concerning the children's behavior. The CBCL (Achenbach et al. 2008) is a questionnaire for the evaluation of dimensional psychopathology in children and adolescents from the age of 6 until the age of 18. It is one of the best studied inventories in psychiatric research and it exists in numerous 
languages with norms (Achenbach et al. 2008, Schmeck et al. 2001). The first part contains questions concerning skills and the second one consists of 120 behavioral items concerning behavioral and emotional problems as well as somatic complaints (118 concerning specific problems and two give the possibility to describe problems which are not specifically asked for). They have to be responded by a parent due to the child's behavior of the last six months. The completion takes about 15-20 minutes. The response scale has a three optional scaling with the code of 2 if the item is often true, 1 for sometimes true and 0 if the item is not true for the child. Some items need to be explained in order to ensure their right interpretation. For example concerning item 66 (repeats certain acts over and over) further explanation by the person completing the questionnaire is often needed in order to recognize if a pathological compulsion is present or just a normal age-dependent behavior. On a higher-level scale it is possible to measure personal skills on 3 scales (activities, social skills and academic achievement) and specific problems on 8 syndrome scales. The latter are combined in three groups: Externalizing, Internalizing and Total Problems. The Externalizing scale includes the syndrome scales Delinquent Behavior and Aggressive Behavior. The scale of Internalizing Problems contains the syndrome scales Anxious/Depressed, Withdrawal and Somatic Complaints. In our study we only used the eight syndrome scales. A computer program calculates the $\mathrm{t}$-score for each scale. If there are more than eight items missing, a scale should not be calculated. A t-score of 50 indicates average functioning in reference to other children of the same age and gender, and every 10 points represents one standard deviation. A tscore on item level higher or equal to $70(=\mathrm{PR} 98)$ is abnormal and further exploration is required. The range between normal and abnormal values is defined between 67 and 70 . On a higher-level scale (internal, external, overall problems) a t-score superior or equal to 63 is suspicious.

\subsection{Statistics}

SPSS for Windows 15.0 statistical package was used for data recording and analyses.

\subsubsection{Analysis of variance}

In the previous study by Roessner et al. (2007) analyses of variance (ANOVA) were performed as several groups were compared. Via ANOVA the impact of ADHD and CTD (respectively ADHD+CTD) on each syndrome scale of the CBCL was examined. Therefore two-way ANOVA for the independent factors CTD (yes/ no) and ADHD (yes/ no) were conducted. If there was no sign of significant interaction, weighted contrasts were generated to compare the relative 
contribution of each factor (CTD vs. ADHD) to the psychopathology in the comorbid group. It was supposed that the difference in the sum of mean values from the CBCL subscales between children with or without CTD does not vary from the difference in the sum of mean values in children with or without ADHD ((ADHD/CTD+CTD)-(ADHD+controls $)=($ ADHD/CTD + ADHD $)-$ (CTD+controls). The level of significance was defined as Alpha=5\% (Roessner et al. 2007). Following the ANOVA and past the ANCOVAs it has been investigated if there were significant interaction effects between CTD and ADHD on any syndrome scale. In this case post-hoc pair-wise comparisons have been conducted in order to find out the direction of the interaction. For this purpose alpha has been adapted.

\subsubsection{Analysis of covariance}

An ANCOVA examines if certain factors have an effect after eliminating the variance for which a covariate is responsible. Therefore the obscuring effects of pre-existing individual differences among subjects are removed. In general the use of covariates improves statistical power, because it accounts for some of the variance in the dependent variable and thus augments the ratio explained by the independent variables. Additional ANCOVAs were conducted to test for possible impacts of unequal distributed factors like learning disorders (Roessner et al. 2007) or OCB. To test the interrelatedness with ADHD or CTD we conducted ANCOVAs with screening instruments of $\mathrm{OCB} / \mathrm{OCD}$ (composed of CBCL items) as covariates. The continuous explanatory variable consisted of the eight syndrome scales (Attention Problems, Withdrawn, Somatic Complaints, Anxious/Depressed, Social Problems, Thought Problems, Delinquent Behavior and Aggressive Behavior). ADHD (yes/no) and CTD (yes/no) were used as independent variables. The $2 \times 2$ design allowed to analyze the contribution of OCB to ADHD-related and CTD-related psychopathology independently. The level of significance was defined as Alpha $=5 \%$.

\subsubsection{Covariates applied in the ANCOVAs}

In this study three different ANCOVAs were conducted. In each a different screening instrument for $\mathrm{OCB} / \mathrm{OCD}$ was used as covariate. All the instruments include various items of the CBCL. One of them, first described by Moll et al. (2000), consists of the following nine items: obsessions (item 9), fears own impulses (31), needs to be perfect (32), compulsions (66), sleeps little (76), stores up unneeded things (83), strange behavior (84), strange ideas (85), and too concerned with neatness or cleanliness (99). Those items belong to the syndrome scales Anxious/Depressed, Other Problems 
and Thought Problems. In the second analysis a covariate first mentioned by Nelson et al. (2001) was used. It consists of eight items and six of them are equal to the items used by Moll et al. (2000): obsessions (item 9), fears own impulses (31), needs to be perfect (32), feels too guilty (52), compulsions (66), strange behavior (84), strange ideas (85) and worries (112) (Nelson et al. 2001). The syndrome scales including those items are Anxious/Depressed and Thought Problems. The latest version of the CBCL-OCS was created by Storch et al. (2006) by dropping the items 32 and 84 from the scale created by Nelson et al (2001).

Table 2.1: OCS score by Nelson et al. (2001)

\begin{tabular}{|l|l|l|}
\hline CBCL item number & CBCL item & CBCL syndrome scale \\
\hline 9 & $\begin{array}{l}\text { Cannot get his/her mind off certain } \\
\text { thoughts; obsessions }\end{array}$ & Thought Problems \\
\hline 31 & Fears own impulses & Anxious/Depressed \\
\hline 32 & Feels he/she has to be perfect & Anxious/Depressed \\
\hline 52 & Feels too guilty & Anxious/Depressed \\
\hline 66 & $\begin{array}{l}\text { Repeats certain acts over and over; } \\
\text { compulsions }\end{array}$ & Thought Problems \\
\hline 84 & Strange behavior & Thought Problems \\
\hline 85 & Strange ideas & Anxious/Depressed \\
\hline 112 & Worries & Thought Problems \\
\hline
\end{tabular}

Table 2.2: OCS score by Moll et al. (2000)

\begin{tabular}{|l|l|l|}
\hline CBCL item number & CBCL item & CBCL syndrome scale \\
\hline 9 & $\begin{array}{l}\text { Cannot get his/her mind off certain } \\
\text { thoughts; obsessions }\end{array}$ & Thought Problems \\
\hline 31 & Fears own impulses & Anxious/Depressed \\
\hline 32 & Feels he/she has to be perfect & Anxious/Depressed \\
\hline 66 & $\begin{array}{l}\text { Repeats certain acts over and over; } \\
\text { compulsions }\end{array}$ & Thought Problems \\
\hline 76 & Sleeps little & Other Problems \\
\hline 83 & Stores up unneeded things & Other Problems \\
\hline 84 & Strange behavior & Thought Problems \\
\hline 95 & Strange ideas Problems \\
\hline 99 & $\begin{array}{l}\text { Too concerned with neatness or } \\
\text { cleanliness }\end{array}$ & Other Problems \\
\hline
\end{tabular}

Table 2.3: OCS score by Storch et al. (2006)

\begin{tabular}{|l|l|l|}
\hline CBCL item number & CBCL item & CBCL syndrome scale \\
\hline 9 & $\begin{array}{l}\text { Cannot get his/her mind off certain } \\
\text { thoughts; obsessions }\end{array}$ & Thought Problems \\
\hline 31 & Fears own impulses & Anxious/Depressed \\
\hline
\end{tabular}




\begin{tabular}{|l|l|l|}
\hline 52 & Feels too guilty & Anxious/Depressed \\
\hline 66 & Compulsions & Thought Problems \\
\hline 85 & Strange ideas & Thought Problems \\
\hline 112 & Worries & Anxious/Depressed \\
\hline
\end{tabular}

\subsubsection{Comparison of the ANOVA results and the ANCOVAs results}

We aimed to investigate if the main effects for ADHD and CTD were mainly influenced by OCB. If OCB contributed to the psychopathology associated with CTD or ADHD, the main effects revealed by the ANCOVAs would considerably differ from the main effects revealed by the ANOVA. We therefore compared the results of the ANOVA and ANCOVA application within each group.

\section{Results}

\subsection{Results of the ANOVA}

Table 3.1: Demographic data of the four groups under investigation; there are no differences between the groups.

\begin{tabular}{|lllll}
\hline Age/Gender & $\begin{array}{l}\mathrm{CTD} \\
(\mathrm{N}=112)\end{array}$ & $\begin{array}{l}\mathrm{CTD}+\mathrm{ADHD} \\
(\mathrm{N}=82)\end{array}$ & $\begin{array}{l}\text { ADHD } \\
(\mathrm{N}=29)\end{array}$ & $\begin{array}{l}\text { Controls } \\
(\mathrm{N}=144)\end{array}$ \\
\hline Age & $\mathbf{1 1 . 1}(\mathrm{SD} 2.6)$ & $\mathbf{1 0 . 7}(\mathrm{SD} 2.3)$ & $\mathbf{1 0 . 5}(\mathrm{SD} 2.5)$ & $\mathbf{1 0 . 4}(\mathrm{SD} 2.4)$ \\
\hline Female & $\mathbf{2 4}(21 \%)$ & $\mathbf{1 4}(17 \%)$ & $\mathbf{2 9}(23 \%)$ & $\mathbf{3 2}(22 \%)$ \\
& & & & $\mathbf{1 1 2}(\mathbf{7 8 \%})$
\end{tabular}

Note: $\mathrm{N}=$ number; $\mathrm{SD}=$ standard deviation

No significant group differences regarding age, $F(3,463)=2.51, p=.06$ or gender, $X^{2}(\mathrm{df}=1$, $\mathrm{N}=467$ ) $=1.09, \mathrm{p}=.21$ could be found. The percentage of learning disorders varied between the groups, with an extraordinary high rate in the control group, $X^{2}(\mathrm{df}=1, \mathrm{~N}=467)=7.56, \mathrm{p}<.01$ (CTDonly 4\%; CTD+ADHD 16\%; ADHD-only 29\%; controls 43\%). Therefore additional 2x2 factorial ANCOVAS with the covariate learning disorder (present or not) were conducted. No effects on any CBCL subscale were revealed. Contrasts were calculated in order to find out if there are different relations between the factors CTD and ADHD to each CBCL subscale. Compared to CTD an ADHD diagnosis showed a stronger relationship to the following subscales: Aggressive Behavior, 
Delinquent Behavior, Attention Problems and Social Problems. Contrasts were not calculated for the subscale Somatic Complaints because the absence of an additive model did not permit it. CTD was not stronger related to any subscale of the CBCL than ADHD.

Table 3.2: Descriptive measures of the ANOVA

\begin{tabular}{|c|c|c|c|c|c|c|c|c|}
\hline & \multicolumn{2}{|c|}{ CTD $(n=112)$} & \multicolumn{2}{|c|}{$\mathrm{CTD}+\mathrm{ADHD}(\mathrm{n}=82)$} & \multicolumn{2}{|c|}{ ADHD $(n=129)$} & \multicolumn{2}{|c|}{ Controls $(\mathrm{n}=144)$} \\
\hline & M & SD & M & SD & M & SD & M & SD \\
\hline Aggressive Behavior & 56.0 & 6.5 & 67.2 & 11.2 & 66.5 & 12.2 & 55.7 & 6.9 \\
\hline Delinquent Behavior & 54.6 & 5.8 & 63.2 & 9.4 & 64.3 & 11.0 & 56.6 & 7.8 \\
\hline Attention Problems & 61.2 & 7.2 & 71.1 & 8.6 & 66.9 & 8.7 & 59.9 & 8.1 \\
\hline Anxious/Depressed & 60.2 & 8.3 & 65.5 & 9.3 & 58.8 & 8.4 & 56.6 & 7.4 \\
\hline Thought Problems & 57.9 & 8.6 & 62.1 & 8.2 & 57.5 & 7.6 & 55.3 & 6.9 \\
\hline Withdrawn & 58.0 & 8.2 & 59.9 & 6.6 & 59.4 & 7.7 & 57.5 & 7.8 \\
\hline Somatic Complaints & 58.5 & 8.1 & 61.3 & 7.8 & 55.7 & 6.8 & 56.3 & 7.1 \\
\hline Social Problems & 59.0 & 9.8 & 66.0 & 11.2 & 62.0 & 10.3 & 56.1 & 7.9 \\
\hline
\end{tabular}

Note: $\mathrm{M}=$ mean, $\mathrm{SD}=$ standard deviation. (Roessner et al. 2007, p. 82)

Table 3.3: Main effects of the ANOVA

\begin{tabular}{|l|l|l|l|l|l|l|l|}
\hline $\left.\begin{array}{l}\text { ANOVA } \\
\text { F }(1,463)\end{array}\right)$ & CTD $(\mathrm{F})$ & CTD+ADHD & F) & ADHD \\
\hline Aggressive Behavior & 0.36 & & 0.04 & & 153.32 & $* * *$ \\
\hline Delinquent Behavior & 3.57 & & 0.42 & & 99.31 & $* * *$ \\
\hline Attention Problems & 12.75 & $* * *$ & 3.36 & & 121.46 & $* * *$ \\
\hline Anxious/Depressed & 43.62 & $* * *$ & 4.30 & $*$ & 23.00 & $* * *$ \\
\hline Thought Problems & 23.84 & $* * *$ & 1.74 & & 18.62 & $* * *$ \\
\hline Withdrawn & 0.44 & & 0.00 & & 6.90 & $* *$ \\
\hline Somatic Complaints & 30.37 & $* * *$ & 6.06 & $*$ & 2.48 & \\
\hline Social Problems & 14.14 & $* * *$ & 0.37 & & 50.74 & $* * *$ \\
\hline
\end{tabular}

Note: $\mathrm{F}=\mathrm{F}-$ value. Effects are from $2 \times 2$ ANOVA with ADHD and CTD as factors. $* * * \mathrm{p}<.001 ; * * \mathrm{p}<.01 ; * \mathrm{p}<.05$ (Roessner et al. 2007, p. 82)

In table 3.3 main effects resulting from the $2 \times 2$ factorial ANOVA for the factor CTD and ADHD are displayed. There were significant main effects for the factor CTD on the following subscales: Attention Problems, Anxious/Depressed, Thought Problems, Somatic Complaints and Social Problems. For the factor ADHD main effects were revealed on all CBCL subscales except for Somatic Complaints. An interaction effect could only be seen on the subscale Anxious/Depressed and Somatic Complaints. 


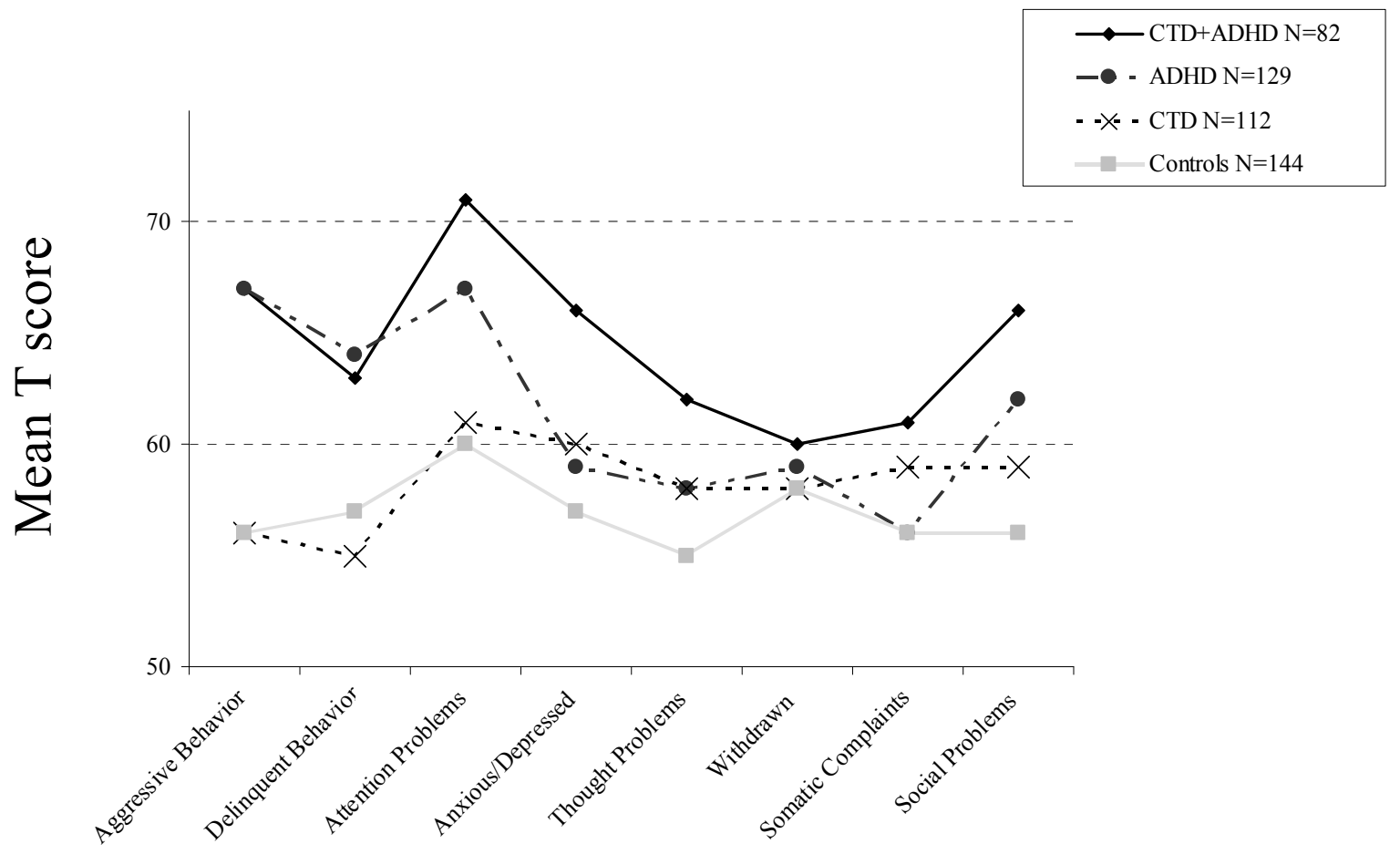

CBCL subscale

Figure 3.2: CBCL profile of the four groups (CTD, CTD+ADHD, $A D H D$, controls). Note: $C B C L=C h i l d$ Behavior Checklist (Achenbach et al. 1991).

\subsection{Results of the three ANCOVAs: Covariates}

In the first equation a CBCL score formed by Nelson et al. (2001) served as the covariate, in the second one the CBCL score created by Moll et al. (2000) was utilized and in the third equation the CBCL score formed by Storch et al. (2006) was used. The 2x2 factorial ANCOVAs revealed for any CBCL subscale significant effects of each score of OCB and OCD respectively $(\mathrm{p}<.05)$.

5.3 Comparing main effects from the $2 \times 2$ ANOVA to those of the three $2 \times 2$ ANCOVAs in terms of the factor CTD

The pattern of psychopathology consisted of resulting main effects on CBCL subscales for the factor CTD. The one resulting from the $2 \times 2$ factorial ANOVA was notably different to the pattern revealed by the three additionally conducted $2 \times 2$ factorial ANCOVAs. The ANOVA revealed main effects for the factor CTD on five of eight subscales: Attention Problems, Anxious/Depressed, Thought Problems, Somatic Complaints and Social Problems. In comparison main effects resulting from the additionally conducted ANCOVAs were seen on fewer subscales. Utilizing the CBCL- 
OCS by Nelson et al. (2001) as covariate, significant effects were found on three subscales: Delinquent Behavior, Withdrawn and Somatic Complaints. The $2 \times 2$ ANCOVA using the CBCLOCS by Moll et al. (2000) as covariate revealed significant main effects on four CBCL subscales: Delinquent Behavior, Anxious/Depressed, Somatic Complaints and Social Problems. The 2x2 factorial ANCOVA applying the CBCL-OCS score by Storch et al. (2006) as covariate also displayed significant main effects on four subscales: Delinquent Behavior, Anxious/Depressed, Withdrawn and Somatic Complaints. The ANOVA revealed significant main effects on Attention Problems and Thought Problems, whereas none of the ANCOVAs showed a main effect on this CBCL scale. On the CBCL scale for Social Problems a main effect was revealed after the conduction of the ANOVA and only after one of the three ANCOVAs. On the CBCL scale Anxious/Depressed the ANOVA revealed a significant main effect, which could also be seen after the conduction of two ANCOVAs. On the scale for Somatic Complaints main effects were shown after the application of the ANOVA and after all of the ANCOVAs. On the CBCL scale Withdrawn no significant effects were shown after the conduction of the ANOVA, whereas two of the ANCOVAs revealed main effects on this syndrome scale. On the Delinquent Behavior scale a similar pattern was displayed: The ANOVA did not reveal a main effect, while all three ANCOVAs revealed main effects. No main effect was demonstrated on the subscale Aggressive Behavior, neither after the ANOVA nor after the three ANCOVAs.

Table 3.4: Main effects for CTD: ANOVA vs. three ANCOVAs (including different OCS scores as covariates: Nelson et al. (2001), Moll et al. (2000) and Storch et al. (2006))

\begin{tabular}{|c|c|c|c|c|c|c|c|c|c|c|c|c|}
\hline CTD & \multicolumn{3}{|c|}{$\begin{array}{l}\text { ANOVA } \\
\mathrm{F}(1,463)\end{array}$} & \multicolumn{9}{|c|}{$\begin{array}{l}\text { ANCOVA } \\
\mathrm{F}(1,463)\end{array}$} \\
\hline Aggressive Behavior & .36 & & .00 & 2.11 & & .01 & 1.94 & & .00 & 1.21 & & .00 \\
\hline Delinquent Behavior & 3.57 & & .01 & 8.28 & $* *$ & .02 & 10.21 & $* *$ & .02 & 6.87 & $* *$ & .02 \\
\hline Attention Problems & 12.75 & $* * *$ & .03 & .82 & & .00 & 2.69 & & .01 & .93 & & .00 \\
\hline Anxious/Depressed ${ }^{2}$ & 43.62 & $* * *$ & .09 & 2.04 & & .00 & 13.97 & $* * *$ & .03 & 4.31 & $*$ & .01 \\
\hline Thought Problems & 23.84 & $* * *$ & .05 & .51 & & .00 & 1.56 & & .00 & .66 & & .00 \\
\hline Withdrawn & .44 & & .00 & 6.44 & $*$ & .01 & 1.84 & & .00 & 4.98 & $*$ & .01 \\
\hline Somatic Complaints ${ }^{1}$ & 30.37 & $* * *$ & .06 & 10.93 & $* *$ & .02 & 18.84 & $* * *$ & .04 & 11.81 & $* *$ & .03 \\
\hline Social Problems & 14.14 & $* * *$ & .03 & 1.74 & & .00 & 3.91 & $*$ & .01 & 1.71 & & .00 \\
\hline
\end{tabular}

Note: F=F-value. The effect sizes presented in Table 3.4 are the partial eta squared. Cohen J (1977) provides the following guidelines for interpreting the eta squared $(\eta 2)$ value: .01-.059=small effect size; .06-.139=medium effect size; $>.14=$ large effect size. ${ }^{* * *} \mathrm{p}<.001 ; * * \mathrm{p}<.01 ; * \mathrm{p}<.051=$ significant interaction effects in all analysis. $2=$ significant interaction effects in the ANOVA and the 2nd ANCOVA. 
5.4 Comparing main effects from the $2 \times 2$ ANOVA to those of the three $2 \times 2$ ANCOVAs in terms of the factor $A D H D$

For the factor ADHD the main effects on the CBCL subscales revealed by the ANOVA were slightly different from those shown after the three ANCOVAs. The ANOVA revealed significant main effects on seven of eight CBCL scales, whereas the conduction of each ANCOVA caused significant main effects on six of eight CBCL scales. On the CBCL scale Withdrawn significant main effects were revealed only after the conduction of the ANOVA, but not after the application of any covariate. On the subscale Somatic Complaints main effects could not be seen, neither after the ANOVA nor past the three ANCOVAs.

Table 3.5: Main effects for ADHD: ANOVA vs. three ANCOVAs (including different OCS scores as covariates: Nelson et al. (2001), Moll et al. (2000) and Storch et al. (2006))

\begin{tabular}{|c|c|c|c|c|c|c|c|c|c|c|c|c|}
\hline ADHD & \multicolumn{3}{|c|}{$\begin{array}{l}\text { ANOVA } \\
\text { F }(1,463)\end{array}$} & ANCOVA & $\begin{array}{l}\text { A } \\
\text { Nelsor }\end{array}$ & & $(F)--$ & Moll & $-\left(\eta^{2}\right)$ & (F) - - - & Storcl & $-\left(\eta^{2}\right)$ \\
\hline Aggressive Behavior & 153.32 & $* * *$ & .25 & 145.20 & $* * *$ & .24 & 135.21 & $* * *$ & .23 & 138.37 & $* * *$ & .23 \\
\hline Delinquent Behavior & 99.31 & $* * *$ & .18 & 92.49 & $* * *$ & .17 & 84.78 & $* * *$ & .16 & 90.37 & $* * *$ & .16 \\
\hline Attention Problems & 121.46 & $* * *$ & .21 & 115.04 & $* * *$ & .20 & 104.13 & $* * *$ & .18 & 107.50 & $* * *$ & .19 \\
\hline Anxious/Depressed ${ }^{2}$ & 23.00 & $* * *$ & .05 & 18.11 & $* * *$ & .04 & 9.71 & $* *$ & .02 & 11.27 & $* *$ & .02 \\
\hline Thought Problems & 18.62 & $* * *$ & .04 & 12.44 & $* * *$ & .03 & 5.65 & $*$ & .01 & 7.04 & $* *$ & .02 \\
\hline Withdrawn & 6.90 & $* *$ & .02 & 2.96 & & .01 & 1.97 & & .00 & 1.97 & & .00 \\
\hline Somatic Complaints ${ }^{1}$ & 2.48 & & .01 & .79 & & .00 & .75 & & .00 & .43 & & .00 \\
\hline Social Problems & 50.74 & $* * *$ & .10 & 43.63 & $* * *$ & .09 & 38.03 & $* * *$ & .08 & 39.32 & $* * *$ & .08 \\
\hline
\end{tabular}

Note: F=F-value. The effect sizes presented in Table 3.5 are the partial eta squared. Cohen J (1977) provides the following guidelines for interpreting the eta squared $(\eta 2)$ value: .01-.059=small effect size; .06-.139=medium effect size; $>.14=$ large effect size. ${ }^{* * *} \mathrm{p}<.001 ;{ }^{*} \mathrm{p}<.01 ;{ }^{*} \mathrm{p}<.051=$ significant interaction effects in all analysis. $2=$ significant interaction effects in the ANOVA and the 2nd ANCOVA.

\subsection{Results of the first ANCOVA with the "Nelson score" as covariate}

\subsubsection{Factor CTD}

Significant main effects for the factor CTD were shown on the subscales Delinquent Behavior, F (1, $463)=8.28, \mathrm{p}=.01, \eta^{2}=.02 ;$ Withdrawn, $F(1,463)=6.44, \mathrm{p}<.05, \eta^{2}=.01$ and Somatic Complaints, $F$ $(1,463)=10.93, \mathrm{p}<.01, \eta^{2}=.02$. On the other syndrome scales no significant main effect was shown: Aggressive Behavior, $F(1,463)=2.11, \mathrm{p}=.15, \eta^{2}=.01$; Attention Problems, $F(1,463)=.82, \mathrm{p}=.37$, $\eta^{2}=.00 ;$ Anxious/Depressed, $F(1,463)=2.04, \mathrm{p}=.15, \eta^{2}=.00$; Thought Problems, $F(1,463)=.51$, 
$p=.48, \eta^{2}=.00$ and Social Problems, $F(1,463)=1.74, p=.19, \eta^{2}=.00$. Compared to the results of the ANOVA the number of syndrome scales showing main effects decreased from five to three.

\subsubsection{Factor ADHD}

For the factor ADHD the additional 2x2 factorial ANCOVA revealed significant main effects on six of eight syndrome scales: Aggressive Behavior, $F(1,463)=145.20, p<.001, \eta^{2}=24$; Delinquent Behavior, $F(1,463)=92.49, \mathrm{p}<.001, \eta^{2}=.17$; Attention Problems, $F(1,463)=115.04, \mathrm{p}<.001$, $\eta^{2}=.20 ;$ Anxious/Depressed, $F(1,463)=18.11, \mathrm{p}<.001, \eta^{2}=.04 ;$ Thought Problems, $F(1,463)$ $=12.44, \mathrm{p}<.001, \eta^{2}=.03$ and Social Problems, $F(1,463)=43.63, \mathrm{p}<.001, \eta^{2}=.09$. On two syndrome scales no significant differences between patients with or without ADHD could be seen: Withdrawn, $F(1,463)=2.96, \mathrm{p}=.09, \eta^{2}=.01$; and Somatic Complaints, $F(1,463)=.79, \mathrm{p}=.38$, $\eta^{2}=.00$. In comparison to the results of the ANOVA, the syndrome scale Withdrawn lost its significant main effect after the application of the covariate.

\subsubsection{Interaction of the factor CTD and ADHD}

On the syndrome scale Somatic Complaints, $F(1,463)=4,73, p=.03, \eta^{2}=.01$ a significant interaction of CTD and ADHD could be seen. The performance of post-hoc pair-wise comparisons revealed the following interaction effects: On the syndrome scale Somatic Complaints children of the control group $(p=.03)$ and of the ADHD group $(p<.01)$ were less affected than children of the comorbid group. All other groups did not differ significantly from each other. On the other syndrome scales no significant interaction was found: Aggressive Behavior, $F(1,463)=.03, \mathrm{p}=.87$, $\eta^{2}=.00$; Delinquent Behavior, $F(1,463)=.21, \mathrm{p}=.65, \eta^{2}=.00$; Attention Problems, $F(1,463)=2.14$, $\mathrm{p}=.14, \eta^{2}=.01 ;$ Anxious/Depressed, $F(1,463)=2.64, \mathrm{p}=.11, \eta^{2}=.01$; Thought Problems, $F(1,463)$ $=.30, \mathrm{p}=.59, \eta^{2}=.00 ;$ Withdrawn, $F(1,463)=.34, \mathrm{p}=.56, \eta^{2}=.00$ and Social Problems, $F(1,463)$ $=.04, \mathrm{p}=.84, \eta^{2}=.00$. Compared to the results of the ANOVA the syndrome scales showing significant interaction between CTD and ADHD were bisected.

\subsection{Results of the second ANCOVA with the "Moll score" as covariate}

\subsubsection{Factor CTD}

There were significant main effects for the factor CTD on four of eight subscales: Delinquent Behavior, $F(1,463)=10.21, \mathrm{p}<.01, \eta^{2}=.02$; Anxious/Depressed, $F(1,463)=13.97, \mathrm{p}<.001, \eta^{2}=.03$; 
Somatic Complaints , $F(1,463)=18.84, \mathrm{p}<.001, \eta^{2}=.04$ and Social Problems, $F(1,463)=3.91$, $\mathrm{p}=.05, \eta^{2}=.01$. On the other syndrome scales no significant main effect was shown: Aggressive Behavior, $F(1,463)=1.94, \mathrm{p}=.17, \eta^{2}=.00$; Attention Problems, $F(1,463)=2.69, \mathrm{p}=.10, \eta^{2}=.01$; Thought Problems, $F(1,463)=1.56, \mathrm{p}=.21, \eta^{2}=.00$ and Withdrawn, $F(1,463)=1.84, \mathrm{p}=.18, \eta^{2}=.00$. Compared to the results of the ANOVA the number of syndrome scales showing main effects decreased from five to four.

\subsubsection{Factor ADHD}

For the factor ADHD there were significant main effects on six of eight syndrome scales: Aggressive Behavior, $F(1,463)=135.21, \mathrm{p}<.001, \eta^{2}=23$; Delinquent Behavior, $F(1,463)=84.78$, $\mathrm{p}<.001, \eta^{2}=.16$; Attention Problems, $F(1,463)=104.13, \mathrm{p}=.001, \eta^{2}=.18$; Anxious/Depressed, $F(1$, $463)=9.71, p<.01, \eta^{2}=.02$; Thought Problems, $F(1,463)=5.65, p=.02, \eta^{2}=.01$ and Social Problems, $F(1,463)=38.03, \mathrm{p}<.001, \eta^{2}=.08$. On two syndrome scales no significant differences between the groups with ADHD as a factor vs. groups without the factor could be seen: Withdrawn, $F(1,463)$ $=1.97, \mathrm{p}=.16, \eta^{2}=.00$ and Somatic Complaints, $F(1,463)=.75, \mathrm{p}=.39, \eta^{2}=.00$. In contrast to the results of the ANOVA, no main effect on the syndrome scale Withdrawn was observable after the inclusion of the covariate.

\subsubsection{Interaction of the factor CTD and ADHD}

Only on two syndrome scales a significant interaction of CTD and ADHD could be seen: Anxious/Depressed, $F(1,463)=5.45, \mathrm{p}=.02, \eta^{2}=.01$ and Somatic Complaints, $F(1,463)=5.91$, $\mathrm{p}=.02, \eta^{2}=.01$. The performance of post-hoc pair-wise comparisons revealed the following interaction effects: On the syndrome scale Somatic Complaints children of the control group $(p<.01)$ and of the ADHD group $(p<.001)$ were less affected than children of the comorbid group. Furthermore it could be seen that children of the CTD group had more problems than children of the ADHD group $(p=.05)$. All other groups did not differ from each other. On the syndrome scale Anxious/Depressed the maximum burden was found in the ADHD+CTD group. The burden was greater than in the control group $(\mathrm{p}<.001)$, the ADHD group $(\mathrm{p}<.001)$ and the CTD group $(\mathrm{p}=.01)$. All other groups did not differ from each other. On the other six syndrome scales no significant interaction was found: Aggressive Behavior, $F(1,463)=.01, p=.94, \eta^{2}=.00$; Delinquent Behavior, $F(1,463)=.33, \mathrm{p}=.56, \eta^{2}=.00 ;$ Attention Problems, $F(1,463)=3.28, \mathrm{p}=.07, \eta^{2}=.01$; Thought Problems, $F(1,463)=2.10, \mathrm{p}=.15, \eta^{2}=.01$; Withdrawn, $F(1,463)=.02, \mathrm{p}=.89, \eta^{2}=.00$ and Social 
Problems, $F(1,463)=.27, \mathrm{p}=.61, \eta^{2}=.00$. Compared to the results of the ANOVA significant interaction could be seen on the same syndrome scales.

\subsection{Results of the third ANCOVA with the "Storch score" as covariate}

\subsubsection{Factor CTD}

There were significant main effects for the factor CTD on four of eight subscales: Delinquent Behavior, $F(1,463)=6.87, \mathrm{p}<.01, \eta^{2}=.02$; Anxious/Depressed, $F(1,463)=4.31, \mathrm{p}=.04, \eta^{2}=.01$; Withdrawn, $F(1,463)=4.98, \mathrm{p}=.03, \eta^{2}=.01$ and Somatic Complaints, $F(1,463)=11.81, \mathrm{p}<.01$, $\eta^{2}=.03$. There was no significant main effect shown on the other syndrome scales: Aggressive Behavior, $F(1,463)=1.21, \mathrm{p}=.27, \eta^{2}=.00$; Attention Problems, $F(1,463)=.93, \mathrm{p}=.34, \eta^{2}=.00$; Thought Problems, $F(1,463)=.66, \mathrm{p}=.42, \eta^{2}=.00$ and Social Problems, $F(1,463)=1.71, \mathrm{p}=.19$, $\eta^{2}=.00$. Compared to the results of the ANOVA the number of syndrome scales showing main effects decreased from five to four.

\subsubsection{Factor ADHD}

For the factor ADHD there were significant main effects on six out of eight syndrome scales: Aggressive Behavior, $F(1,463)=138.37, \mathrm{p}<.001, \eta^{2}=.23$; Delinquent Behavior, $F(1,463)=90.37$, $\mathrm{p}<.001, \eta^{2}=.16$; Attention Problems, $F(1,463)=107.50, \mathrm{p}=.001, \eta^{2}=.19 ;$ Anxious/Depressed, $F(1$, $463)=11.27, p=.01, \eta^{2}=.02$; Thought Problems, $F(1,463)=7.04, p=.01, \eta^{2}=.02$ and Social Problems, $F(1,463)=39.32, \mathrm{p}<.001, \eta^{2}=.08$. On two syndrome scales no significant differences between the groups with ADHD as a factor vs. groups without the factor could be seen: Withdrawn, $F(1,463)=1.97, \mathrm{p}=.16, \eta^{2}=.00$ and Somatic Complaints, $F(1,463)=.43, \mathrm{p}=.52, \eta^{2}=.00$. In contrast to the results of the ANOVA, the syndrome scale Withdrawn did not reveal a significant main effect.

\subsubsection{Interaction of the factor CTD and ADHD}

Only on one syndrome scale a significant interaction of CTD and ADHD could be seen: Somatic Complaints, $F(1,463)=4,77, \mathrm{p}=.03, \eta^{2}=.01$. The performance of post-hoc pair-wise comparisons revealed the following interaction effects: On the syndrome scale Somatic Complaints children of the control group $(\mathrm{p}=.03)$ and of the ADHD group $(\mathrm{p}<.01)$ were less affected than children of the comorbid group. All other groups did not differ from each other. On the following syndrome scales 
no significant interaction was found: Aggressive Behavior, $F(1,463)=.01, p=.91, \eta^{2}=.00$; Delinquent Behavior, $F(1,463)=.25, \mathrm{p}=.62, \eta^{2}=.00$; Attention Problems, $F(1,463)=2.15, \mathrm{p}=.14$, $\eta^{2}=.01 ;$ Anxious/Depressed, $F(1,463)=2.68, \mathrm{p}=.10, \eta^{2}=.01$; Thought Problems, $F(1,463)=.29$, $\mathrm{p}=.59, \eta^{2}=.00$; Withdrawn, $F(1,463)=.29, \mathrm{p}=.59, \eta^{2}=.00$ and Social Problems, $F(1,463)=.03$, $\mathrm{p}=.85, \eta^{2}=.00$. Compared to the results of the ANOVA the number of syndrome scales showing significant interaction between CTD and ADHD was bisected.

5.8 Comparison of changes in psychopathology profiles provoked by the application of covariates in the groups including CTD as a factor vs. groups including ADHD as a factor

In the groups including CTD as a factor (CTD and CTD+ADHD) the application of covariates caused a much greater change in the pattern of psychopathology than the application of the same covariates to the groups including ADHD as a factor (ADHD and ADHD+CTD). In the groups with CTD as a factor changes in psychopathology through the application of covariates seemed to depend more on the type of covariate used, whereas changes of psychopathology in the groups with $\mathrm{ADHD}$ as a factor changed in a similar way, irrespective of the applied covariate.

\section{Discussion}

\subsection{CTD and ADHD as a factor}

The aim of the previous study (Roessner et al. 2007) was to specify the contribution of CTD and ADHD to the psychopathological profile of the comorbid group (CTD+ADHD). The psychopathological profiles of four large groups, which are of comparable size and similar in sex and age (CTD-only, ADHD-only, CTD+ADHD, controls), were measured by the eight subscales of the CBCL. Roessner et al. used a 2x2 factorial design and calculated contrasts with the factors CTD and ADHD (Roessner et al. 2007). Compared to previous studies, this design allowed a separate analysis of main effects of both disorders, whereby it was possible to statistically asses the contribution of each factor in case of comorbidity. As a result, all but one subscale of the CBCL showed main effects of ADHD. For the factor CTD, significant main effects were revealed on the following CBCL subscales: Attention Problems, Anxious/Depressed, Thought Problems, Somatic Complaints and Social Problems. Comparing the four clinically diagnosed groups the highest level of psychopathology was found in patients with ADHD+CTD. Except for the subscales Somatic Complaints and Anxious/Depressed no interaction effect was revealed. The calculated contrasts 
showed the greater importance of ADHD, compared to CTD, in the psychopathology of the CTD + ADHD group. On the subscales Aggressive Behavior, Delinquent Behavior, Attention Problems and Social Problems a stronger impact of an ADHD diagnosis compared to CTD was observed. CTD and ADHD were both related to internalizing psychopathology of children in the comorbid group. From a psychopathological point of view, the results of the previous study strongly support an additive model for the co-occurrence of CTD and ADHD (Roessner et al. 2007).

\subsection{CBCL subscales as covariates}

If more complex psychopathological conditions are assumed, an interactive model has to be considered. Peterson et al. mentioned that OCB/OCD symptoms are often related to tics and ADHD (Peterson et al. 2001). They could therefore be responsible for some psychopathological effects shown on the CBCL subscales of our sample. In order to further clarify the contribution of OCB to the psychopathology of children with CTD and/or ADHD, we applied three different subscales of the CBCL as covariates, which have been studied as screening instruments for OCB/OCD. As in the previous study (Roessner et al. 2007), we analyzed group differences among four large, age- and sex-similar groups of comparable size, without any further confounding psychiatric conditions. The profile of psychopathology of each patient was also measured by the subscales of the CBCL. According to our hypothesis, the results showed that OCB has a major influence on the psychological problems and social competence of children with CTD and/or ADHD. These findings are in line with a study by Peterson et al. (2001), which confirm the interrelatedness of tics, OCD and ADHD. From their large prospective sample of children, they had concluded that the cooccurrence of ADHD and tics in clinical patients could result in part from a complex sharing during development of numerous psychopathological risk factors such as OCD (Peterson et al. 2001). Banaschewski et al. also assumed a complex psychopathological pattern of tic, OCB, impulsivity and internalizing symptomatology, which requires discriminating assessment and treatment (Banaschewski et al. 2003). Our findings confirmed their hypothesis, since we found that OCB had a greater influence on CTD-related psychopathology than on the psychopathological profile associated with ADHD. 


\subsection{Results of the ANOVA}

Comparing descriptive measures of the $2 \times 2$ ANOVA as shown in table 3.2 it is evident that the CTD-only group was more affected in all CBCL subscales, except for "Delinquent Behavior", than the control group. It should be stressed that the mean of all children diagnosed with CTD did not exceed the cut-off value in any of the syndrome scales. Of the four clinically diagnosed groups the highest levels of psychopathology could be seen in patients with CTD+ADHD, except on the subscale Delinquent Behavior. The mean of all children in the CTD+ADHD group had a pathological value on the syndrome scales Aggressive Behavior, Delinquent Behavior, Attention Problems, Anxious/Depressed and Social Problems. As expected, the ADHD-only group also had higher levels on all subscales, except for Somatic Complaints, than the control group. The ADHDonly group exceeded the cut-off value on the subscales Aggressive Behavior, Delinquent Behavior and Attention Problems showing the major influence of ADHD on those behaviors. The high level of psychopathology in the ADHD group on the subscale Delinquent Behavior and the low level of psychopathology in the CTD group on the same subscale support the hypothesis of a high impact of ADHD in the comorbid group on this subscale.

Still, the present study focused on the interrelatedness of the factors ADHD and CTD. In table 3.3 the main effects for the factor ADHD and CTD are displayed. The numerous main effects of the factor ADHD (on seven of eight syndrome scales) revealed the extensive impact of ADHD in almost all domains. CTD showed significant main effects, exhibiting the influence of the CTD diagnoses on the psychopathology of children, on behaviors united on five of eight subscales of the CBCL. Therefore CTD also has a strong impact on the psychopathology of children, but not as broad as in children with an ADHD diagnosis. Interaction effects between the factors could only be seen on two of eight subscales (Anxious/Depressed and Somatic Complaints), which supports the hypothesis of an additive model. On the subscale Somatic Complaints the children of the comorbid group were significantly more affected than the children in the ADHD group and in the control group. Furthermore the mean of the CTD group on the same subscale was significantly higher, representing a higher level of psychopathology than the mean of children in the ADHD group.

\subsection{Results of the ANCOVAs}

\subsubsection{Factor CTD}

Main findings of the present study, as displayed in table 3.4, were the following:

- The introduction of each covariate (operationalised by three different CBCL scores to detect $\mathrm{OCB} / \mathrm{OCD}$ ) had major influences on the pattern of psychopathology in children with CTD. 
Comparing the results of the three ANCOVAs with those of the ANOVA, on seven of eight syndrome scales of the CBCL significant differences were found. In line with literature this result points out the great contribution of OCB to psychopathology of CTD. Robertson mentioned before that OCB is integral to TS (Robertson 2000) and a study by Kurlan et al. supported an association between TD and OCB (Kurlan et al. 2002).

- The application of the different covariates transformed the pattern of psychopathology in different ways. Already slight changes of the covariate had a great impact on psychopathology.

- The direction of influence of OCB was not identical on all subscales of the CBCL. On most CBCL syndrome scales the application of a covariate led to a reduction of psychopathology, but on a couple of syndrome scales it caused an increase of psychopathology. The reduction of psychopathology could be interpreted as the existence of an additive burden in children with CTD+OCB compared to patients with CTD-only. The increase of psychopathology on some CBCL subscales could lead to the assumption that the co-occurrence of OCB in CTD patients could mask or compensate symptoms of CTD.

The inclusion of the three covariates caused the disappearance of main effects on the subscale Attention Problems (Nelson: $F=.82, p=.37$; Moll: $F=2.69, p=.10$; Storch: $F=.93, p=.34$ ) as well as on Thought Problems (Nelson: $F=51, p=.48$; Moll: $F=1.56, p=.21$; Storch: $F=.66, p=.42$ ). The results suggest that the psychopathology gathered by these syndrome scales was caused by subclinical OCD and leads to the assumption that attention problems are more likely to be caused by sorrows (as a symptom of OCB) rather than by tics. These results also approve the supposition that symptoms leading to significant effects on the CBCL scale Thought Problems are mainly caused by characteristics of OCB and not by CTD. This has been indicated but not statistically tested by other authors before. Kurlan et al. assumed that subjects with OCD might endorse some of the items scored as Thought Problems in patients with TS (Kurlan et al. 2002). Another study suggested that the positive correlation between tic severity and the CBCL subscale Thought Problems is mainly due to OCB (Hoekstra et al. 2004). More recently Ivarsson et al. revealed a positive relationship between OCD severity and the number of thought problems in OCD patients (Ivarsson et al. 2008).

A similar pattern could be observed on the syndrome scale Social Problems. Applications of a covariate led to a meaningful decrease of psychopathology. Main effects of the ANOVA were not significant anymore or its F-values were reduced as a result of the inclusion of the covariates. Similarly, after ANCOVAs using the score created by Nelson et al. (2001) and Storch et al. (2006) the significance of results in psychopathology disappeared (Nelson: $F=1.74, p=.19$; Storch: $F=1.71$, $\mathrm{p}=.19$ ), whereas the result of the ANCOVA utilizing the score created by Moll et al. (2000) still 
exposed a weak significance in the CTD group (Moll: $\mathrm{F}=3.91, \mathrm{p}=.05$ ). This comparison suggested that OCB causes more social problems than tics do.

The pattern of psychopathology on the subscale Delinquent Behavior, revealed by the different statistical analyses, displayed a contrast to the results mentioned before. There was no significant main effect on this syndrome scale after the ANOVA. In contrast the three ANCOVAs displayed significant effects (Nelson: $\mathrm{F}=8.28, \mathrm{p}=.01$; Moll: $\mathrm{F}=10.21, \mathrm{p}<.01$; Storch: $\mathrm{F}=6.87, \mathrm{p}<.01$ ). The result showed that the presence of OCB could inhibit the appearance of psychopathology on this scale. Contrarily pure CTD (or CTD-only) caused psychopathology on this scale, indicating that tics could be one of the main contributing factor to "Delinquent Behavior". Similar influences of tics on this scale were shown by Kurlan et al. (2002) before. They found a higher frequency of scores above cut-off on the CBCL scale Delinquent Behavior in children with tics compared to children without tics (Kurlan et al. 2002). In their previous study Roessner et al. reported an important impact of ADHD on this subscale (Roessner et al. 2007), which leads to the hypothesis that hidden ADHD characteristics could have also caused an effect on this scale.

For the groups with CTD as a factor similar effects could be seen on the syndrome scale Withdrawn. After the ANOVA CTD did not show a main effect on this subscale. In contrast the ANCOVAs using the CBCL-OCS by Nelson et al. (2001) and the CBCL-OCS by Storch et al. (2006) as covariates did show small, but significant main effects (Nelson: $F=6.44, p<.05$; Storch: $\mathrm{F}=4.98, \mathrm{p}=.03$ ). The results of the ANCOVA applying the CBCL-OCS by Moll et al. (2000) as covariate remained without a significant effect of CTD (Moll: $F=1.84, p=.18$ ). This result led to the assumption that tics rather than OCB cause withdrawal, which is in contrast to another study. Kasius et al. investigated the convergence between the CBCL and the clinical-diagnostic approach of the DSM. In their study the Withdrawn scale predicted anxiety and affective disorders (Kasius et al. 1997).

A different pattern of psychopathology could be seen for the subscale Aggressive Behavior. The application of the ANCOVAs did not lead to any significant difference on this syndrome scale irrespective of the kind of covariate used. After the analyses with the "Nelson score" (F=2.11, $\mathrm{p}=.15)$, the "Moll score" $(\mathrm{F}=1.94, \mathrm{p}=.17)$ and the "Storch score" $(\mathrm{F}=1.21, \mathrm{p}=.27)$ no significant differences were identified, indicating the major effect of CTD and the not noteworthy one of OCB on this subscale. Kurlan et al. already suggested a strong impact of TD on this scale, reporting a higher frequency of scores above cut-off on the CBCL scale Aggressive Behavior in children with tics compared to children without tics (Kurlan et al. 2002). Contrarily Banaschewski et al. found a stronger impact (higher scores on this CBCL subscale) for patients with TD+OCD compared to patients with TD-only (Banaschewski et al. 2003). This is in line with a study by Stephens and 
Sandor, who found higher scores for "Aggressive Behavior" in children with TS and comorbid OCD (or ADHD or both) compared to patients with pure TS (Stephens and Sandor 1999). Another study revealed less inhibitory dysfunction in individuals with TS alone than those with TS and a comorbidity (ADHD, OCD or both) (Ozonoff et al. 1998). Ivarsson et al. figured that the cause for higher scores on the subscale Aggressive Behavior in Tic/Tourette patients might be the lack of control associated with these disorders (Ivarsson et al. 2008).

Concerning the subscales Anxious/Depressed and Somatic Complaints a more sophisticated examination was required. In all three ANCOVAs significant interaction effects on the syndrome scale Somatic Complaints for the children with CTD were found. Post-hoc pair-wise comparisons revealed a similar pattern of psychopathology within the groups (CTD, CTD+ADHD, ADHD, controls). No matter which covariate had been applied to the ANCOVA, the CTD+ADHD group was repeatedly more affected than the ADHD as well as the control group. The pattern of psychopathology on the syndrome scale Anxious/Depressed as displayed in table 3.4 is quite inconsistent. After the application of the covariate created by Nelson et al. (2001) no psychopathology could be seen for the CTD groups anymore (Nelson: $F=2.04, p=.15$ ). In contrast the application of the covariate formed by Moll et al. (2000) revealed interaction effects on this scale. The ANCOVA using the covariate formed by Storch et al. (2006) also revealed a reduction of significance, but the CBCL profile still remained with a small, significant psychopathology (Storch: $\mathrm{F}=4.31, \mathrm{p}=.04$ ). The decrease or even discontinuation of psychopathology in the CBCL resulting from the ANCOVAs indicates that anxious/depressed symptoms are more typical among patients with OCB $+\mathrm{CTD}$ compared to patients with CTD-only. This is in line with other studies. Banaschewski et al. revealed higher scores on the CBCL subscale Anxious/Depressed for patients with OCD+TD compared to patients with TD-only (Banaschewski et al. 2003). Termine et al. outlined pathological and significantly higher mean scores on the Anxious/Depressed scale for patients with TS+OCD compared to patients with TS-only (Termine et al. 2006). Results of posthoc pair-wise comparisons have shown the maximum burden in the ADHD+CTD group, which was significantly greater than in each of the other groups. This is in line with another study. Spencer et al. found out that children with TS+ADHD had lower psychosocial functioning than children with ADHD alone (Spencer et al. 1998). Another study revealed that children with TS and ADHD show lower social adaptation and that they are afflicted with more externalizing and internalizing behavior problems than children with TS-only (Carter et al. 2000).

Our study displayed that the covariate created by Nelson et al. (2001) mainly changed the profile of psychopathology. On four syndrome scales the significant effect revealed by the ANOVA was removed through the application of the score created by Nelson et al. (2001) as covariate. On one 
syndrome scale the effect became less significant. Two scales which did not show a significant effect before revealed one after the ANCOVA. The profile of psychopathology resulting from the ANOVA was changed more when the score from Nelson et al. (2001) was applied to the ANCOVA than after the implementation of the score formed by Storch et al. (2006). On three syndrome scales a significant effect (shown as a result of the ANOVA) was removed by the application of the covariate formed by Storch et al. (2006). Two scales showed a less significant effect after the ANCOVA and two other syndrome scales became significant through the ANCOVA. The utilization of the score created by Moll et al. (2000) as covariate changed the profile of psychopathology the least. On two scales a significant effect was lost and on another scale the effect became less significant. On the syndrome scale Delinquent Behavior a significant effect was only shown after the ANCOVA. This effect was demonstrated after each ANCOVA irrespective of the covariate used.

\subsubsection{Factor ADHD}

The results of the ANOVA and the three different ANCOVAs for children diagnosed with ADHD are displayed in table 3.5. Our study led to the following main results:

- The introduction of a covariate had influences on the pattern of psychopathology in children with ADHD. Comparing the results of the three ANCOVAs with those of the ANOVA, three out of eight syndrome scales revealed significant differences. This showed the important influence of OCB, not only on the psychopathology of CTD patients, but also on children with ADHD.

- Comparing the changes in the pattern of psychopathology (from the results of the ANOVA to those of the three ANCOVAs) in the groups with ADHD as a factor to the ones of the groups including children with CTD, the variances were a lot smaller in the ADHD group. This result supported our hypothesis that OCB has a smaller effect on the psychopathology of children with ADHD compared to the effect on CTD patients.

- The pattern of psychopathology as a result of the ANOVA was transformed in a similar way irrespective of the kind of covariate used. This is in contrast to the changes in psychopathology revealed by the application of the ANCOVAs to the groups with CTD as a factor. In these groups small differences within the covariates transformed the pattern of psychopathology in quite different ways. It could be concluded that the greater influence of OCB on CTD makes their pattern of psychopathology more sensible to little differences within the covariate. 
- The performance of each ANCOVA led to a reduction of psychopathology on some of the CBCL syndrome scales. This result suggests an additive burden of patients with OCB + ADHD compared to ADHD-only. Other studies had also shown that comorbidity increases the behavioral symptom severity of ADHD (Ulloa et al. 2006, Drabick et al. 2004). Instead this finding is not congruent with the study by Volk et al., who showed that comorbidities do not significantly increase impairment among ADHD patients (Volk et al. 2006). In contrast, results of Tzang and Chang (2009) demonstrated a significant difference in the CBCL scale scores depending on the present subtype of ADHD. Their results suggested a synergistic effect of the ADHD subtype and comorbidities on behavioral symptom severity (Tzang and Chang 2009). A significant increase of psychopathology by the application of a covariate could not be seen in the ADHD group, assuming that OCB does not mask, compensate or alleviate symptoms caused by ADHD.

In detail: Only on the subscale Withdrawn the main effect of ADHD was absent after the conduction of the ANCOVAs (Nelson: $F=2.96, p=.09$; Moll: $F=1.97, p=.16$; Storch: $F=1.97$, $\mathrm{p}=$.16). This indicates that OCB might determine how withdrawn an ADHD child is. ADHD-only does not seem to have a great effect on this scale. The great influence of anxiety disorders on this CBCL subscale has also been suggested in a previous study (Kasius et al. 1997).

On the syndrome scale Thought Problems a somewhat similar pattern was found. The application of the score created by Moll et al. (2000) as covariate led to a relevant decrease of psychopathology (Moll: $\mathrm{F}=5.65, \mathrm{p}=.02$ ). The utilization of the score formed by Storch et al. (2006) also led to a decrease in psychopathology (Storch: $\mathrm{F}=7.04, \mathrm{p}<.01$ ). The application of the score mentioned by Nelson et al. (2001) hardly changed the result of the ANOVA on this syndrome scale (Nelson: $\mathrm{F}=12.44, \mathrm{p}<.001)$. This result suggests that thought problems are caused partly by both disorders (OCB and ADHD), because the highest impact was found for OCB+ADHD.

For the subscales Anxious/Depressed and Somatic Complaints a more differentiated examination had to be done. As mentioned above on the syndrome scale Somatic Complaints significant interaction effects of CTD and ADHD could be found in all ANCOVAs. Results of post-hoc pairwise comparisons were described earlier in the text.

The pattern of psychopathology on the syndrome scale Anxious/Depressed is inconsistent and depending on the kind of covariate applied. After the insertion of the score created by Storch et al. (2006) as covariate a significant decrease in psychopathology could be seen for groups of children with ADHD (Storch: $\mathrm{F}=11.27, \mathrm{p}<.01$ ). In contrast the utilization of the score mentioned by Nelson et al. (2001) as covariate did not lead to a significant difference compared to the result of the ANOVA (Nelson: $\mathrm{F}=18.11, \mathrm{p}<.001)$. The ANCOVA applying the score by Moll et al. (2000) as 
covariate showed significant interaction effects. Because of the different results on this subscale, a general conclusion could not be drawn.

On the CBCL syndrome scale Aggressive Behavior the realization of the ANCOVAs did not lead to a significant difference in psychopathology irrespective of the covariate used. For the application of the score formed by Nelson et al. (2001) as covariate $(\mathrm{F}=145.20, \mathrm{p}<.001)$ as well as for the one created by Moll et al. (2000) $(\mathrm{F}=135.21, \mathrm{p}<.001)$ and Storch et al. (2006) $(\mathrm{F}=138.37, \mathrm{p}<.001)$ no significant differences to the results of the ANOVA were identified, showing a negligible influence of OCB on this subscale. The great influence of ADHD on this subscale has been described in a recent study, where patients with the association of TS and ADHD showed significantly higher mean scores than those patients without ADHD (Termine et al. 2006). Previously Stephens and Sandor reported that aggressive behavior in TS may be associated with comorbid ADHD (Stephens and Sandor 1999). Ivarsson et al. figured that the cause of higher scores on the Aggressive Behavior subscale in ADHD patients might be the lack of control associated with this disorder (Ivarsson et al. 2008).

The application of any covariate did not change the level of significance importantly on the syndrome scales Delinquent Behavior (Nelson: $\mathrm{F}=92.49, \mathrm{p}<.001$; Moll: $\mathrm{F}=84.78, \mathrm{p}<.001$; Storch: $\mathrm{F}=90.37, \mathrm{p}<.001$ ), Attention Problems (Nelson: $\mathrm{F}=115.04, \mathrm{p}<.001$; Moll: $\mathrm{F}=104.13, \mathrm{p}<.001$; Storch: $\mathrm{F}=107.50, \mathrm{p}<.001$ ) or Social Problems (Nelson: $\mathrm{F}=43.63, \mathrm{p}<.001$; Moll: $\mathrm{F}=38.03, \mathrm{p}<.001$; Storch: $\mathrm{F}=39.32, \mathrm{p}<.001$ ). On all these scales a high significant effect was shown as a result of the ANOVA as well as a result of all three ANCOVAs. This suggests that ADHD has the main impact on these scales and the influence of OCB is not noteworthy. The great impact of ADHD on the subscale Attention Problems has been mentioned by other authors before (Termine et al. 2006, Kasius et al. 1997).

\subsection{Limitations}

This study has several limitations that require careful consideration in the interpretation of the results. First, our studied population was a clinically referred sample. As in many clinical studies with inpatient design, it is possible that these children and adolescents had more behavioral and emotional problems than non-referred individuals. Therefore, our results may not be generalizable to non-referral populations. Second, the results should not be generalized to different age groups. Chang et al. found significant negative correlations between the age of TS patients and some CBCL subscales (Chang et al. 2008). Singer and Rosenberg also found an association between a TS subject's age and rates of abnormality on some CBCL scales (Singer and Rosenberg 1989). Third, 
the behavioral symptom severity measured by the CBCL is known to be influenced by the subtype of ADHD according to the DSM-IV classification (Tzang and Chang 2009); therefore, the results may not be entirely transferable to other ADHD subtypes. Fourth, only the CBCL subscale by Moll et al. (2000) was created for the screening of OCB, while the CBCL subscales by Nelson et al. (2001) and Storch et al. (2006) were established to detect OCD. Moreover, in our sample none of the patients suffered from OCD, because patients with any comorbid disorder apart from CTD and ADHD were excluded from the study. Instead, we used the CBCL-OCS for ANCOVAs in samples with a subclinical OCD or OCB. However, Van Grootheest et al. identified the CBCL-OCS as a useful instrument to identify children at risk for, but not yet expressing, DSM OCD (Van Grootheest et al. 2007). Therefore, all conclusions about the impact of comorbid OCB/OCD on the psychopathology of CTD and ADHD are based on the assumption that OCB forms a continuum, with full-blown OCD being more severe than subclinical OCD but sharing the same characteristics. After all, systematical errors need to be mentioned. Data obtained from the CBCL can be influenced by the person who completed the questionnaire (mother or father), the level of severity within a disorder, and whether the subject was receiving psychotropic medication at the time (Rosenberg et al. 1984). In this study, we did not control for the parent who answered the CBCL questions. Due to missing values in our data set, severity ratings of CTD and ADHD symptoms were not included in our study, despite their importance as clinical markers for psychopathology. This limitation seems to be important, as Cardona et al. described a positive correlation between the YGTSS scores and two scales of the CBCL (Externalizing Symptoms and Total Problems) (Cardona et al. 2004). Cardona et al. (2004) also found a positive correlation between three CBCL scores (Internalizing Symptoms, Attention Problems, Anxious/Depressed) and the duration of the TD. This finding indicates that several types of behaviors and psychopathologies seem to be related to the duration of the TD, instead of children's age or the TD itself (Cardona et al. 2004). In the present study, we did not control for the duration of the TD.

A further limitation of the present study is that the screening instruments of OCB/OCD (which served as covariates) and the psychopathology scales (which were used as dependent variable) both derive from the CBCL. This might be viewed as a problem of circularity. However, the items integrated in the screening instruments are only part of two of the eight syndrome scales (Anxious/Depressed and Thought Problems), while the influence of the covariate is observable on almost all of the subscales. This demonstrates that the contributions of the covariates are not only an artifact of circularity. The screening instruments of OCB/OCD have been evaluated in several studies. Still, it remains possible that they over- or under-identify cases in other samples. 


\section{Conclusion}

Our results are in line with our hypothesis that tics, $\mathrm{OCB} / \mathrm{OCD}$, and ADHD are interrelated. Along with Roessner et al. (2007), the present study underlines the complexity of the psychopathological pattern of children with CTD and/or ADHD. It indicates that in average the psychopathology cannot be explained only by the core symptoms of both disorder, but must be explained also by the contribution of subclinical OCD. In order to be aware of all symptoms and problems of a patient, a careful assessment of the whole psychopathology is necessary. This is especially true for patients with subclinical (OCB) and clinical OCD, because they are often secretive about their symptoms (Ivarsson and Larsson 2008). In addition to relieving the patient's current symptoms, early detection and initiation of treatment can improve clinical outcomes (Pelchat 2002, Walitza et al. 2011). Especially in terms of CTD+comorbidities, the most obvious disorder might not be the one a child suffers from the most. In these cases, a treatment of the main diagnosis or the core symptoms of CTD might not help the patient with his or her major problems. Our results indicate that it can be more important for $\mathrm{CTD}$ children to treat their $\mathrm{OCB}$ than to treat their tics. Only with the knowledge of the whole psychopathology it is possible to plan an optimal treatment for each individual child. Especially for an inexperienced clinician, it is important to have an instrument for the assessment of possible influences of subclinical OCD on the psychopathological profile. As mentioned before, in clinical routine it is often not possible to use an extensive diagnostic instrument like the CY-BOCS. Therefore, one of the scores developed by Nelson et al. (2001), Moll et al. (2000), or Storch et al. (2006) could be very useful for estimating OCB in daily clinical practice. 


\section{Appendix: German version of the CBCL}

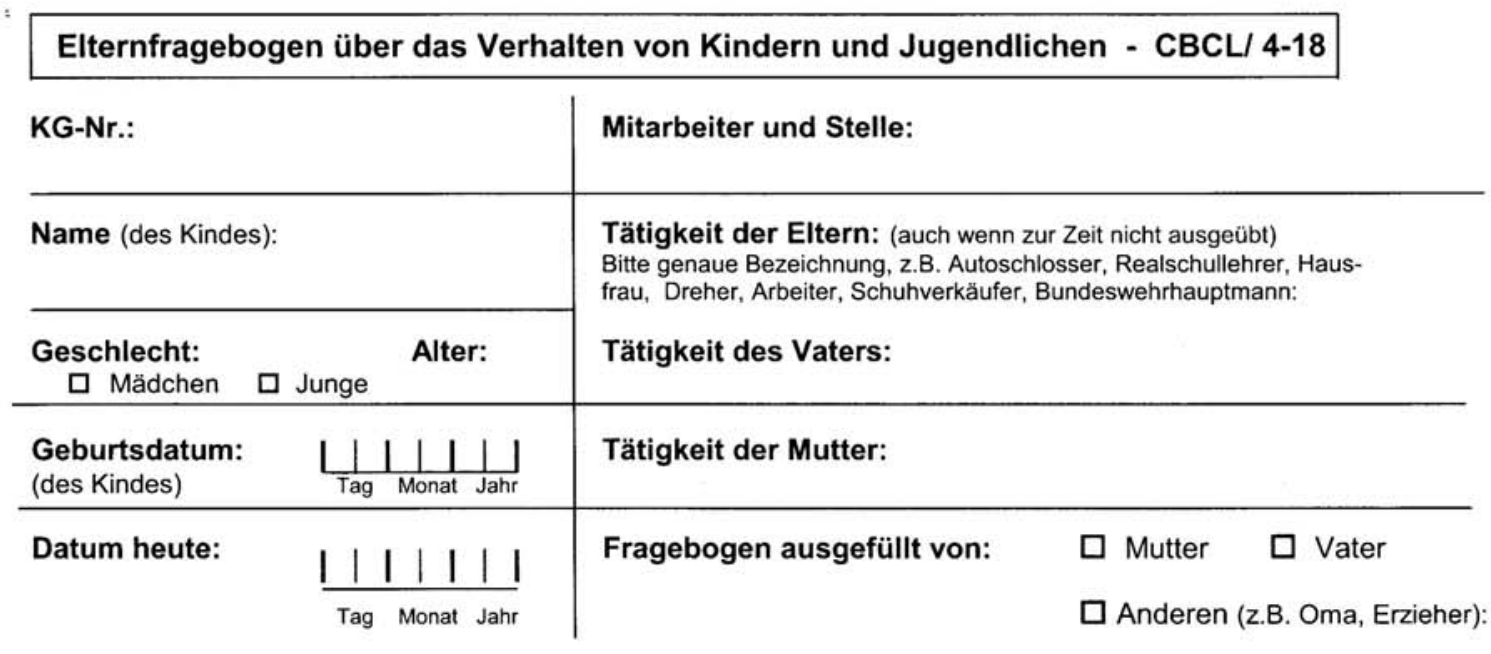

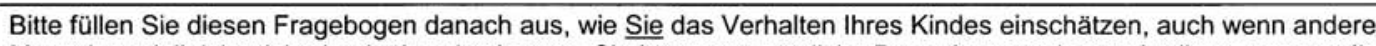
Menschen vielleicht nicht damit übereinstimmen. Sie können zusätzliche Bemerkungen dazu schreiben, wenn es Ihnen erforderlich erscheint.

\begin{tabular}{|c|c|c|c|c|c|c|c|c|}
\hline \multirow{2}{*}{$\begin{array}{l}\text { I. Nennen Sie bitte die Sportarten, } \\
\text { die Ihr Kind am liebsten ausübt, } \\
\text { z.B. Fußball, Radfahren, } \\
\text { Schwimmen, Tischtennis usw.. } \\
\square \text { keine }\end{array}$} & \multicolumn{4}{|c|}{$\begin{array}{l}\text { Wieviel Zeit verbringt Ihr Kind } \\
\text { mit dieser Sportart, } \\
\text { verglichen mit Gleichaltrigen? }\end{array}$} & \multicolumn{4}{|c|}{$\begin{array}{l}\text { Wie gut beherrscht Ihr Kind } \\
\text { diese Sportart, verglichen } \\
\text { mit Gleichaltrigen? }\end{array}$} \\
\hline & $\begin{array}{l}\text { Ich weiß } \\
\text { es nicht }\end{array}$ & weniger & $\begin{array}{l}\text { gleich } \\
\text { viel }\end{array}$ & mehr & $\begin{array}{l}\text { Ich weiß } \\
\text { es nicht }\end{array}$ & $\begin{array}{l}\text { weniger } \\
\text { gut }\end{array}$ & $\begin{array}{l}\text { gleich } \\
\text { gut }\end{array}$ & besser \\
\hline a. & $\square$ & $\square$ & 口 & $\square$ & 口 & $\square$ & 口 & ㅁ \\
\hline b. & 口 & $\square$ & 口 & $\square$ & 口 & $\square$ & $\square$ & $\square$ \\
\hline c. & $\square$ & $\square$ & $\square$ & $\square$ & $\square$ & $\square$ & $\square$ & 口 \\
\hline
\end{tabular}

II. Nennen Sie bitte die Lieblingsaktivitäten, Hobbies oder Spiele Ihres Kindes, z.B. Klavierspielen, Briefmarkensammeln, Singen, Lesen, mit Puppen oder Autos spielen usw. (außer Sport, Radiohören, Fernsehen).

\section{$\square$ keine}

a.

b.

c.

\section{Wieviel Zeit verbringt Ihr Kind} damit, verglichen mit Gleichaltrigen?

Ich weiß weniger gleich mehr
es nicht

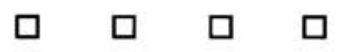

ㅁ $\square \square \square$

$\square \quad \square \quad \square \quad \square$
Wie gut beherrscht Ihr Kind diese Aktivität,verglichen mit Gleichaltrigen?

Ich weiß weniger gleich besser 
III.Gehört Ihr Kind irgendwelchen

Organisationen, Vereinen oder Gruppen an?

$\square$ keine

a.

b.

c.
Wie aktiv ist lhr Kind dort, verglichen mit Gleichaltrigen?

Ich weiß weniger gleich aktiver

es nicht aktiv aktiv

$\begin{array}{llll}\square & \square & \square & \square \\ \square & \square & \square & \square\end{array}$

IV. Welche Arbeiten oder Pflichten übernimmt Ihr Kind innerhalb oder außerhalb des Haushalts, z.B. Spülen,

Kinderhüten, Zeitungen austragen usw.?

Wie gut verrichtet Ihr Kind

diese Arbeiten oder Pflichten,

verglichen mit Gleichaltrigen?

$\square$ keine

Ich weiß weniger gleich besser

es nicht gut gut

a.

$\square \quad \square \quad \square \quad \square$

b.

$\square \square \square \square$

c.

$\square \quad \square \quad \square \quad \square$

V. 1. Wieviele Freunde hat Ihr Kind?

$\square$ Keine $\square$ einen $\square$ zwei bis drei $\square$ vier oder mehr (bitte Geschwister nicht mitzählen)

2. Wie oft pro Woche unternimmt lhr Kind etwas mit seinen Freunden außerhalb der Schulstunden? (bitte Geschwister nicht mitzählen)

$\square$ weniger als einmal

Dein- bis zweimal

$\square$ dreimal oder häufiger

VI. Verglichen mit Gleichaltrigen:

schlechter

etwa gleich

besser
a. Wie verträgt sich Ihr Kind mit den Geschwistern?
b. Wie verträgt sich Ihr Kind mit anderen Kindern/Jugendlichen?
c. Wie verhält sich lhr Kind gegenüber den Eltern?
d. Wie spielt oder arbeitet Ihr Kind alleine?

口.

口

$\square \square$ Einzelkind 
VII. 1. Gegenwärtige Schulleistungen (für Kinder ab 6 Jahren):

$\square$ besucht keine Schule

a. Lesen, Deutsch

b. Sachkunde, Geschichte oder Sozialkunde

c. Rechnen oder Mathematik

d. Naturwissenschaften (falls zutreffend)

andere Fächer

(wie Erdkunde,

Fremdsprachen:

nicht Fächer wie

Kunst, Musik,

Sport usw.) e.

g.

$$
\text { ungenügend } \begin{gathered}
\text { unterdurch- } \\
\text { schnittlich }
\end{gathered} \quad \begin{gathered}
\text { durch- } \\
\text { schnittlich }
\end{gathered} \quad \begin{gathered}
\text { überdurch- } \\
\text { schnittlich }
\end{gathered}
$$

\section{Besucht Ihr Kind eine Sonderschule bzw. hat es eine besondere Art der Beschulung (z.B. Integrationskind)?}

$\square$ nein $\square$ ja, bitte genaue Beschreibung:

3. Hat Ihr Kind eine Klasse wiederholt? $\square$ nein $\square$ ja, welche und warum:

4. Sind bei Ihrem Kind schon einmal Lernschwierigkeiten oder andere Probleme in der Schule aufgetreten?

$\square$ nein $\square$ ja, bitte beschreiben:

Wann fingen die Probleme an?

Haben diese Probleme aufgehört? $\square$ nein $\square$ ja, wann:

Hat Ihr Kind eine Krankheit, körperliche oder geistige Beeinträchtigung oder Behinderung? $\square$ nein $\square$ ja

wenn ja, bitte beschreiben:

Worüber machen Sie sich bei Ihrem Kind die meisten Sorgen?

Was gefällt Ihnen an Ihrem Kind am besten?

Utheberrechtlich geschutat

(C) T.M. Achenbach, 1991, und

Arbeitsgruppe Deutsche Child Behavior Checklist
Nachdruck verboten! 
Es folgt eine Liste von Eigenschaften und Verhaltensweisen, die bei Kindern und Jugendlichen auftreten können. Nach jeder Eigenschaft finden Sie die Ziffern 0, 1, 2. Beantworten Sie bitte für jede Eigenschaft, ob sie jetzt oder innerhalb der letzten 6 Monate bei Ihrem Kind zu beobachten war. Wenn diese Eigenschaft genau so oder häufig zu beobachten war, kreuzen Sie die Ziffer 2 an, wenn die Eigenschaft etwas oder manchmal auftrat, die Ziffer 1, wenn Sie für Ihr Kind nicht zutrifft, die Ziffer 0 . Beantworten Sie bitte alle Fragen so gut Sie können, auch wenn Ihnen einige für Ihr Kind unpassend erscheinen.

\begin{tabular}{|lll|}
\hline $\begin{array}{c}0=\text { nicht zutreffend } \\
\text { (soweit bekannt) }\end{array}$ & $1=$ etwas oder manchmal zutreffend & 2 = genau oder häufig zutreffend \\
\hline
\end{tabular}

1. Verhält sich zu jung für sein/ihr Alter

2. Leidet unter Heuschnupfen oder anderen Allergien; bitte beschreiben:

3. Streitet oder widerspricht viel.

4. Hat Asthma

5. Bei Jungen: verhält sich wie ein Mädchen

Bei Mädchen: verhält sich wie ein Junge

6. Entleert den Darm außerhalb der Toilette, kotet ein.....

7. Gibt an, schneidet auf

8. Kann sich nicht konzentrieren, kann nicht lange aufpassen

9. Kommt von bestimmten Gedanken nicht los: bitte beschreiben:

10. Kann nicht stillsitzen, ist unruhig

oder überaktiv

11. Klammert sich an Erwachsene oder ist zu abhängig

12. Klagt über Einsamkeit.

.012

012

.012

.....012

.012

......012

.012

.012

3. Ist verwirt oder zerstreut

14. Weint viel

15. Ist roh zu Tieren oder quält sie ................................ 012

16. Ist roh oder gemein zu anderen oder schüchtert sie ein .

.012

17. Hat Tagträume oder ist gedankenverloren ...............012

18. Verletzt sich absichtlich oder versucht Selbstmord.

.012

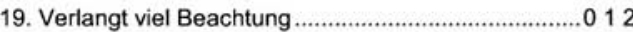

20. Macht seine/ihre eigenen Sachen kaputt...................0 012

21. Macht Sachen kaputt, die den Eltern.

Geschwistern oder anderen gehören.

.012

22. Gehorcht nicht zu Hause

.012

23. Gehorcht nicht in der Schule ..................................... 012

24. I It schlecht ................................................................. 012

25. Kommt mit anderen Kindern/Jugendlichen nicht aus...

26. Scheint sich nicht schuldig zu fühlen, wenn er/sie sich schlecht benommen hat

27. Ist leicht eifersüchtig

28. IBt oder trinkt Dinge, die nicht zum Essen oder Trinken geeignet sind; bitte beschreiben: (keine Süßigkeiten angeben)

29. Fürchtet sich vor bestimmten Tieren, Situationen oder Plätzen (Schule ausgenommen); bitte beschreiben:

30. Hat Angst, in die Schule zu gehen. 012

31. Hat Angst, etwas Schlimmes zu denken oder zu tun.

32. Glaubt, perfekt sein zu müssen
33. Fühlt oder beklagt sich, dass niemand inn/sie liebt

34. Glaubt, andere wollen ihm/ihr

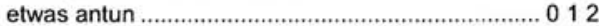

35. Fühit sich wertlos oder unterlegen ........................... 012

36. Verletzt sich häufig ungewollt, neigt

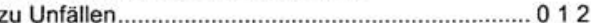

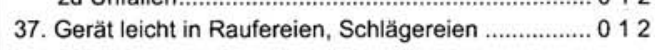

38. Wird viel gehänselt................................................. 012

39. Hat Umgang mit anderen, die in Schwierigkeiten geraten ......................................... 012

40. Hört Geräusche oder Stimmen, die nicht da sind; bitte beschreiben:

41. Ist impulsiv oder handelt, ohne zu

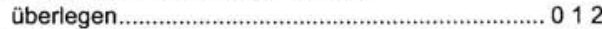

42. Ist lieber allein als mit anderen zusammen .............. 012

43. Lügt, betrügt oder schwindelt ................................... 012

44. Kaut Fingernägel ....................................................... 012

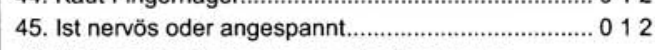

46. Hat nervöse Bewegungen oder Zuckungen (betrifft nicht die unter 10 erwähnte Zappeligkeit); bitte beschreiben:

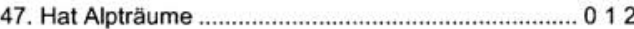

48. Ist bei anderen Kindern/Jugendlichen

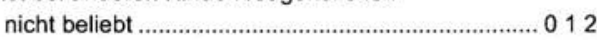

49. Leidet an Verstopfung............................................. 012

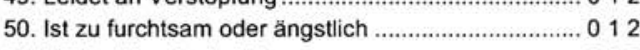

51. Fühlt sich schwindelig ............................................ 012

52. Hat zu starke Schuldgefühle ................................. 012

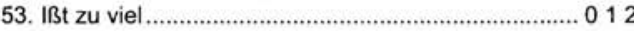

54. Ist immer müde ......................................................... 012

55. Hat Übergewicht.......................................................... 012

56. Hat folgende Beschwerden ohne bekannte körperliche Ursachen:

a) Schmerzen (außer Kopf- oder

Bauchschmerzen) ............................................. 012

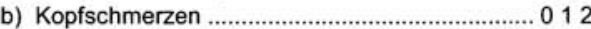

c) Übelkeit............................................................. 012

d) Augenbeschwerden (ausgenommen solche, die durch Brille korrigiert sind); bitte beschreiben:

e) Hautausschläge oder andere Hautprobleme ............................................................ 012

f) Bauchschmerzen oder Magenkrämpfe................ 012

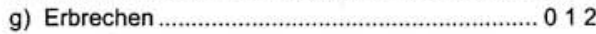

h) andere Beschwerden; bitte beschreiben _ .012 


\begin{tabular}{|c|c|c|}
\hline $\mathbf{0}=\begin{array}{c}\text { nicht zutreffend } \\
\text { (soweit bekannt) }\end{array}$ & 1 = etwas oder manchmal zutreffend & 2 = genau oder häufig zutreffend \\
\hline
\end{tabular}

57. Greift andere körperlich an . 012

58. Bohrt in der Nase, zupft oder kratzt sich an Körperstellen; bitte beschreiben:

59. Spielt in der Öffentlichkeit an den eigenen

Geschlechtsteilen....

60 . Spielt zu viel an den eigenen

Geschlechtsteilen

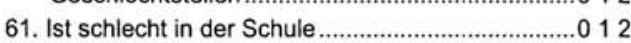

62. Ist körperlich unbeholfen oder ungeschickt ..........012

63. Ist lieber mit älteren Kindern oder Jugendlichen als mit Gleichaltrigen zusammen ................0 12

64. Ist lieber mit Jüngeren als mit Gleichaltrigen zusammen

65. Weigert sich zu sprechen ......................................... 012

66. Tut bestimmte Dinge immer und immer wieder, wie unter einem Zwang; bitte beschreiben:

67. Läuft von zu Hause weg........................................... 012

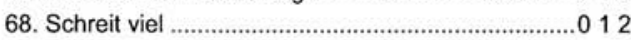

69. Ist verschlossen, behält Dinge für sich ..................012

70. Sieht Dinge, die nicht da sind; bitte beschreiben:

71. Ist befangen oder wird leicht verlegen ...................012

72. Zündelt gerne oder hat schon Feuer gelegt............012

73. Hat sexuelle Probleme; bitte beschreiben: __ ..012

74. Produziert sich gern oder spielt den Clown ...........0 12

75. Ist schüchtern oder zaghaft.................................... 012

76. Schläft weniger als die meisten Gleichaltrigen ......012

77. Schläft tagsüber und/oder nachts mehr als die meisten Gleichaltrigen; bitte beschreiben:_ ..012

78. Schmiert oder spielt mit Kot ....................................... 012

79. Hat Schwierigkeiten beim Sprechen; bitte beschreiben:

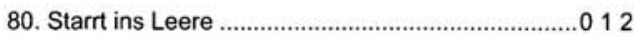

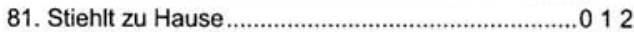

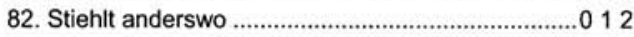

83. Hortet Dinge, die er/sie nicht braucht; bitte beschreiben:

84. Verhält sich seltsam oder eigenartig; bitte beschreiben:

85. Hat seltsame Gedanken oder Ideen; bitte beschreiben:

86. Ist störrisch, mürrisch oder reizbar.

87. Zeigt plötzliche Stimmungs- oder Gefühlswechsel.

88. Schmollt viel oder ist leicht eingeschnappt ............012

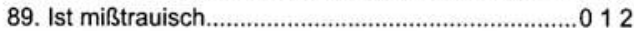

90. Flucht oder gebraucht obszöne (schmutzige) Wörter
91. Spricht davon, sich umzubringen. 012

92. Redet oder wandelt im Schlaf; bitte beschreiben: .012

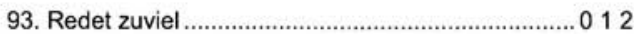

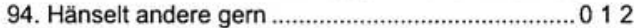

95. Hat Wutausbrüche oder hitziges

Temperament .......................................................... 012

96. Denkt zuviel an Sex................................................. 012

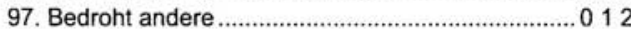

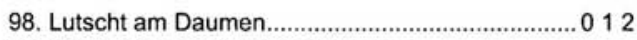

99. Ist zu sehr auf Ordentlichkeit oder Sauberkeit bedacht ............................................. 012

100. Hat Schwierigkeiten mit dem Schlafen; bitte beschreiben:

101. Schwänzt die Schule (auch einzelne Schulstunden)

102. Zeigt zu wenig Aktivität, ist zu langsam oder träge.

103. Ist unglücklich, traurig oder niedergeschlagen...

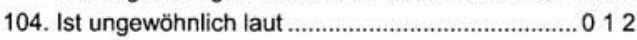

105. Trinkt Alkohol, nimmt Drogen oder mißbraucht Medikamente; bitte beschreiben: 012

106. Richtet mutwillig Zerstörungen an .

107. Näßt bei Tag ein

012

108. Näßt im Schlaf ein .

012

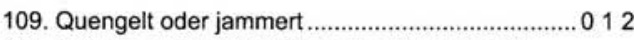

110. Bei Jungen: Möchte lieber ein Mădchen sein Bei Mädchen: Möchte lieber ein Junge sein......... 012

111. Zieht sich zurück, nimmt keinen Kontakt zu anderen auf .

112. Macht sich zuviel Sorgen ...

113. Bitte beschreiben Sie hier Probleme Ihres Kindes, die bisher noch nicht erwähnt wurden:

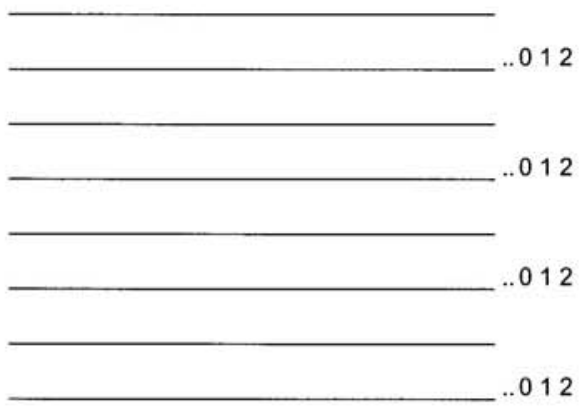

--> Bitte überprüfen Sie, ob Sie alle Fragen beantwortet haben.

.-> Unterstreichen Sie bitte diejenigen Probleme, die Ihnen Sorgen machen.

Vielen Dank ! 


\section{References}

Achenbach TM, Howell CT, Quay HC, Conners CK (1991): National survey of problems and competencies among four-to sixteen-year-olds: parents' reports for normative and clinical samples. Monogr Soc Res Child Dev 투, 1-131

Achenbach TM, Becker A, Dopfner M, Heiervang E, Roessner V, Steinhausen HC, Rothenberger A (2008): Multicultural assessment of child and adolescent psychopathology with ASEBA and SDQ instruments: research findings, applications, and future directions. J Child Psychol Psychiatry $\underline{49}, 251-275$

Allsopp M, Verduyn C (1989): A follow-up of adolescents with obsessive-compulsive disorder. $\mathrm{Br}$ J Psychiatry 154, 829-34

Althoff RR, Rettew DC, Boomsma DI, Hudziak JJ (2009): Latent class analysis of the Child Behavior Checklist Obsessive-Compulsive Scale. Compr Psychiatry 무, 584-592

American-Psychiatric-Association: Diagnostic and statistical manual of mental disorders; 4th edition; American Psychiatric Press, Washington 1994

American-Psychiatric-Association: Diagnostic and statistical manual of mental disorders; 4th edition Text Revision; American Psychiatric Press, Washington 2000

Apter A, Fallon TJ, Jr., King RA, Ratzoni G, Zohar AH, Binder M, Weizman A, Leckman JF, Pauls DL, Kron S et al. (1996): Obsessive-compulsive characteristics: from symptoms to syndrome. J Am Acad Child Adolesc Psychiatry 35, 907-912

Arnold PD, Ickowicz A, Chen S, Schachar R (2005): Attention-deficit hyperactivity disorder with and without obsessive-compulsive behaviours: clinical characteristics, cognitive assessment, and risk factors. Can J Psychiatry $\underline{50}$, 59-66

Banaschewski T, Siniatchkin M, Uebel H, Rothenberger A (2003): [Compulsive phenomena in children with tic disorder and attention deficit-hyperactive disorder]. Z Kinder Jugendpsychiatr Psychother 31, 203-211

Berg CZ, Whitaker A, Davies M, Flament MF, Rapoport JL (1988): The survey form of the Leyton Obsessional Inventory-Child Version: norms from an epidemiological study. J Am Acad Child Adolesc Psychiatry 27, 759-763

Black DW, Gaffney GR (2008): Subclinical obsessive-compulsive disorder in children and adolescents: additional results from a "high-risk" study. CNS Spectr $\underline{13}, 54-61$

Brynska A, Wolanczyk T (2005): Epidemiology and phenomenology of obsessive-compulsive disorder in non-referred young adolescents: a Polish perspective. Eur Child Adolesc Psychiatry $14,319-327$

Burns GL, Formea GM, Keortge S, Sternberger LG (1995): The utilization of nonpatient samples in the study of obsessive compulsive disorder. Behav Res Ther 33, 133-144

Calvocoressi L, Lewis B, Harris M, Trufan SJ, Goodman WK, Mcdougle CJ, Price LH (1995): Family accommodation in obsessive-compulsive disorder. Am J Psychiatry 152, 441-443

Cardona F, Romano A, Bollea L, Chiarotti F (2004): Psychopathological problems in children affected by tic disorders - study on a large Italian population. Eur Child Adolesc Psychiatry 13, 166-171

Caron C, Rutter M (1991): Comorbidity in child psychopathology: concepts, issues and research strategies. J Child Psychol Psychiatry $\underline{32}$, 1063-1080

Carter AS, Pollock RA (2000): Obsessive compulsive disorder in childhood. Curr Opin Pediatr $\underline{12}$, 325-330

Carter AS, O'donnell DA, Schultz RT, Scahill L, Leckman JF, Pauls DL (2000): Social and emotional adjustment in children affected with Gilles de la Tourette's syndrome: associations with ADHD and family functioning. Attention Deficit Hyperactivity Disorder. J Child Psychol Psychiatry $\underline{41}, 215-223$

Cath DC, Spinhoven P, Van De Wetering BJ, Hoogduin CA, Landman AD, Van Woerkom TC, Roos RA, Rooijmans HG (2000): The relationship between types and severity of repetitive 
behaviors in Gilles de la Tourette's disorder and obsessive-compulsive disorder. J Clin Psychiatry $\underline{61}, 505-513$

Cath DC, Spinhoven P, Van Woerkom TC, Van De Wetering BJ, Hoogduin CA, Landman AD, Roos RA, Rooijmans HG (2001): Gilles de la Tourette's syndrome with and without obsessivecompulsive disorder compared with obsessive-compulsive disorder without tics: which symptoms discriminate? J Nerv Ment Dis $\underline{189}, 219-228$

Chang HL, Liang HY, Wang HS, Li CS, Ko NC, Hsu YP (2008): Behavioral and emotional problems in adolescents with Tourette syndrome. Chang Gung Med J 31, 145-152

Coffey BJ, Biederman J, Geller D, Frzier J, Spencer T, Doyle R, Gianini L, Small A, Frisone DF, Magovcevic M et al. (2004): Reexamining Tic persistence and Tic-associated impairment in Tourette's Disorder: findings from a naturalistic follow-up study. J Nerv Ment Dis 192, 776-780

Cohen AJ, Leckman JF (1992): Sensory phenomena associated with Gilles de la Tourette's syndrome. J Clin Psychiatry 53, 319-323

Cohen J: Statistical power analysis for the behavioral sciences. Revised edition; Academic Press, New York 1977

Cohen P, Cohen J, Kasen S, Velez CN, Hartmark C, Johnson J, Rojas M, Brook J, Streuning EL (1993): An epidemiological study of disorders in late childhood and adolescence--I. Age- and gender-specific prevalence. J Child Psychol Psychiatry $\underline{34}$, 851-867

Crino R, Slade T, Andrews G (2005): The changing prevalence and severity of obsessivecompulsive disorder criteria from DSM-III to DSM-IV. Am J Psychiatry 162, 876-882

Degonda M, Wyss M, Angst J (1993): The Zurich Study. XVIII. Obsessive-compulsive disorders and syndromes in the general population. Eur Arch Psychiatry Clin Neurosci 243, 16-22

Dilling H, Mombour W, Schmidt MH: Internationale Klassifikation psychischer Störungen, ICD10, Kapitel V (F); Huber, Bern 2000

Döpfner M, Rothenberger A (2007): Tic- und Zwangsstörungen. Kindh Entwick 16(2), 75-95

Döpfner M, Roessner V, Woitecki K, Rothenberger A; Tic-Störungen; Hogrefe, Göttingen 2010

Drabick DA, Gadow KD, Carlson GA, Bromet EJ (2004): ODD and ADHD symptoms in Ukrainian children: external validators and comorbidity. J Am Acad Child Adolesc Psychiatry 43, 735-743

Eapen V, Robertson MM, Alsobrook JP, 2nd, Pauls DL (1997): Obsessive compulsive symptoms in Gilles de la Tourette syndrome and obsessive compulsive disorder: differences by diagnosis and family history. Am J Med Genet 74, 432-438

Elia J, Ambrosini PJ, Rapoport JL (1999): Treatment of attention-deficit-hyperactivity disorder. N Engl J Med 340, 780-788

Englert E, Jungmann J, Rotthaus W, Wienand F, Lam L, Poustka F (1996): Glossar zur Basisdokumentation Kinder- und Jugendpsychiatrie. Z Kinder Jugendpsychiatr Psychother $\underline{3}$, 3851

Faraone SV, Sergeant J, Gillberg C, Biederman J (2003): The worldwide prevalence of ADHD: is it an American condition? World Psychiatry 2, 104-113

Faraone SV, Biederman J, Mick E (2006): The age-dependent decline of attention deficit hyperactivity disorder: a meta-analysis of follow-up studies. Psychol Med 36, 159-165

Fish DR, Sawyers D, Allen PJ, Blackie JD, Lees AJ, Marsden CD (1991): The effect of sleep on the dyskinetic movements of Parkinson's disease, Gilles de la Tourette syndrome, Huntington's disease, and torsion dystonia. Arch Neurol $\underline{48}, 210-214$

Flament MF, Whitaker A, Rapoport JL, Davies M, Berg CZ, Kalikow K, Sceery W, Shaffer D (1988): Obsessive compulsive disorder in adolescence: an epidemiological study. J Am Acad Child Adolesc Psychiatry 27, 764-771

Freeman RD (2007): Tic disorders and ADHD: Answers from a worl-wide clinical dataset on Tourette syndrome. Eur Child Adolesc Psychiatry 16 Suppl 1, 15-23

Freeman RD, Fast DK, Burd L, Kerbeshian J, Robertson MM, Sandor P (2000): An international perspective on Tourette syndrome: selected findings from 3,500 individuals in 22 countries. Dev Med Child Neurol $\underline{42}$, 436-447 
Gaub M, Carlson CL (1997): Gender differences in ADHD: a meta-analysis and critical review. J Am Acad Child Adolesc Psychiatry $\underline{36}$, 1036-1045

Geller DA, Biederman J, Reed ED, Spencer T, Wilens TE (1995): Similarities in response to fluoxetine in the treatment of children and adolescents with obsessive-compulsive disorder. J Am Acad Child Adolesc Psychiatry $\underline{34}, 36-44$

Geller DA, Biederman J, Griffin S, Jones J, Lefkowitz TR (1996): Comorbidity of juvenile obsessive-compulsive disorder with disruptive behavior disorders. J Am Acad Child Adolesc Psychiatry $\underline{35}, 1637-1646$

Geller DA, Biederman J, Faraone SV, Cradock K, Hagermoser L, Zaman N, Frazier JA, Coffey BJ, Spencer TJ (2002): Attention-deficit/hyperactivity disorder in children and adolescents with obsessive-compulsive disorder: fact or artifact? J Am Acad Child Adolesc Psychiatry 41, 52-58

Geller DA, Coffey B, Faraone S, Hagermoser L, Zaman NK, Farrell CL, Mullin B, Biederman J (2003): Does comorbid attention-deficit/hyperactivity disorder impact the clinical expression of pediatric obsessive-compulsive disorder? CNS Spectr $\underline{8}, 259-264$

Geller DA, Doyle R, Shaw D, Mullin B, Coffey B, Petty C, Vivas F, Biederman J (2006): A quick and reliable screening measure for OCD in youth: reliability and validity of the obsessive compulsive scale of the Child Behavior Checklist. Compr Psychiatry 47, 234-240

George MS, Trimble MR, Ring HA, Sallee FR, Robertson MM (1993): Obsessions in obsessivecompulsive disorder with and without Gilles de la Tourette's syndrome. Am J Psychiatry 150, 93-97

Gibbs N (1996): Nonclinical populations in research on obsessive-compulsive disorder. A critical review. Clin Psychol Rev 16(8), 729-773

Gilbert D (2006): Tretment of children and adolescents with tics and Tourette syndrome. J Child Neurol 21, 690-700

Gillberg C, Gillberg IC, Rasmussen P, Kadesjo B, Soderstrom H, Rastam M, Johnson M, Rothenberger A, Niklasson L (2004): Co-existing disorders in ADHD - implications for diagnosis and intervention. Eur Child Adolesc Psychiatry 13 Suppl 1, I80-92

Goldman LS, Genel M, Bezman RJ, Slanetz PJ (1998): Diagnosis and treatment of attentiondeficit/hyperactivity disorder in children and adolescents. Council on Scientific Affairs, American Medical Association. JAMA 279, 1100-1107

Goyette CH, Conners CK, Ulrich RF (1978): Normative data on revised Conners Parent and Teacher Rating Scales. J Abnorm Child Psychol $\underline{6}$, 221-236

Grabe HJ, Meyer C, Hapke U, Rumpf HJ, Freyberger HJ, Dilling H, John U (2001): Lifetimecomorbidity of obsessive-compulsive disorder and subclinical obsessive-compulsive disorder in Northern Germany. Eur Arch Psychiatry Clin Neurosci 251, 130-135

Hanna GL (1995): Demographic and clinical features of obsessive-compulsive disorder in children and adolescents. J Am Acad Child Adolesc Psychiatry 34, 19-27

Heyman I, Fombonne E, Simmons H, Ford T, Meltzer H, Goodman R (2001): Prevalence of obsessive-compulsive disorder in the British nationwide survey of child mental health. $\mathrm{Br} \mathrm{J}$ Psychiatry 179, 324-329

Hoekstra PJ, Steenhuis MP, Troost PW, Korf J, Kallenberg CG, Minderaa RB (2004): Relative contribution of attention-deficit hyperactivity disorder, obsessive-compulsive disorder, and tic severity to social and behavioral problems in tic disorders. J Dev Behav Pediatr 25, 272-279

Holzer JC, Goodman WK, Mcdougle CJ, Baer L, Boyarsky BK, Leckman JF, Price LH (1994): Obsessive-compulsive disorder with and without a chronic tic disorder. A comparison of symptoms in 70 patients. Br J Psychiatry 164, 469-473

Honjo S, Hirano C, Murase S, Kaneko T, Sugiyama T, Ohtaka K, Aoyama T, Takei Y, Inoko K, Wakabayashi S (1989): Obsessive-compulsive symptoms in childhood and adolescence. Acta Psychiatr Scand $\underline{80}, 83-91$

Hudziak JJ, Van Beijsterveldt CE, Althoff RR, Stanger C, Rettew DC, Nelson EC, Todd RD, Bartels M, Boomsma DI (2004): Genetic and environmental contributions to the Child Behavior 
Checklist Obsessive-Compulsive Scale: a cross-cultural twin study. Arch Gen Psychiatry $\underline{61}$, 608-616

Hudziak JJ, Althoff RR, Stanger C, Van Beijsterveldt CE, Nelson EC, Hanna GL, Boomsma DI, Todd RD (2006): The Obsessive Compulsive Scale of the Child Behavior Checklist predicts obsessive-compulsive disorder: a receiver operating characteristic curve analysis. J Child Psychol Psychiatry 47, 160-166

Hurtig T, Ebeling H, Taanila A, Miettunen J, Smalley SL, Mcgough JJ, Loo SK, Jarvelin MR, Moilanen IK (2007): ADHD symptoms and subtypes: relationship between childhood and adolescent symptoms. J Am Acad Child Adolesc Psychiatry 46, 1605-1613

Ivarsson T, Larsson B (2008): The Obsessive-Compulsive Symptom (OCS) scale of the Child Behavior Checklist: a comparison between Swedish children with Obsessive-Compulsive Disorder from a specialized unit, regular outpatients and a school sample. J Anxiety Disord 22, 1172-1179

Ivarsson T, Melin K, Wallin L (2008): Categorical and dimensional aspects of co-morbidity in obsessive-compulsive disorder (OCD). Eur Child Adolesc Psychiatry 17, 20-31

Karno M, Golding JM, Sorenson SB, Burnam A (1988): The epidemiology of obsessivecompulsive disorder in five US communities. Arch Gen Psychiatry 4도 1094-1099

Kasius MC, Ferdinand RF, Van Den Berg H, Verhulst FC (1997): Associations between different diagnostic approaches for child and adolescent psychopathology. J Child Psychol Psychiatry $\underline{38}$, 625-632

Khalifa N: Tourette Syndrome and Tic Disorders in a Swedish School Population. Digital Comprehensive Summaries of Uppsala Dissertations from faculty of Medicine 2006, Uppsala 2006

Kotsopoulos S, Spivak M (2001): Obsessive-compulsive symptoms secondary to methylphenidate treatment. Can J Psychiatry $\underline{46}, 89$

Kouris S (1998): Methylphenidate-induced obsessive-compulsiveness. J Am Acad Child Adolesc Psychiatry $\underline{37}, 135$

Kuperman S (2002): Tic disorders in the adolescent. Adolesc Med 13, 537-551

Kurlan R, Como PG, Miller B, Palumbo D, Deeley C, Andresen EM, Eapen S, Mcdermott MP (2002): The behavioral spectrum of tic disorders: a community-based study. Neurology $\underline{59}$, 414420

Lahey BB, Pelham WE, Chronis A, Massetti G, Kipp H, Ehrhardt A, Lee SS (2006): Predictive validity of ICD-10 hyperkinetic disorder relative to DSM-IV attention-deficit/hyperactivity disorder among younger children. J Child Psychol Psychiatry $\underline{47}, 472-479$

Leckman JF (2002): Tourette's syndrome. Lancet 360, 1577-1586

Leckman JF (2003): Phenomenology of tics and natural history of tic disorders. Brain Dev 25 Suppl $1,24-28$

Leckman JF, Riddle MA, Hardin MT, Ort SI, Swartz KL, Stevenson J, Cohen DJ (1989): The Yale Global Tic Severity Scale: initial testing of a clinician-rated scale of tic severity. J Am Acad Child Adolesc Psychiatry 28, 566-573

Leckman JF, Grice DE, Barr LC, De Vries AL, Martin C, Cohen DJ, Mcdougle CJ, Goodman WK, Rasmussen SA (1994): Tic-related vs. non-tic-related obsessive compulsive disorder. Anxiety 1 , 208-215

Leckman JF, Pauls DL, Zhang H, Rosario-Campos MC, Katsovich L, Kidd KK, Pakstis AJ, Alsobrook JP, Robertson MM, Mcmahon WM et al. (2003): Obsessive-compulsive symptom dimensions in affected sibling pairs diagnosed with Gilles de la Tourette syndrome. Am J Med Genet B Neuropsychiatr Genet 116B, 60-68

Leonard HL, Goldberger E, Rapoport J, Cheslow D, Swedo S (1990): Childhood rituals: normal development or obsessive-compulsive symptoms? J Am Acad Child Adolesc Psychiatry 29, 1723 
Leonard HL, Lenane MC, Swedo SE, Rettew DC, Gershon ES, Rapoport JL (1992): Tics and Tourette's disorder: a 2- to 7-year follow-up of 54 obsessive-compulsive children. Am J Psychiatry $\underline{149}, 1244-1251$

Leonard HL, Swedo SE, Lenane MC, Rettew DC, Hamburger SD, Bartko JJ, Rapoport JL (1993): A 2- to 7-year follow-up study of 54 obsessive-compulsive children and adolescents. Arch Gen Psychiatry $\underline{50}, 429-439$

Lewin AB, Chang S, Mccracken J, Mcqueen M, Piacentini J (2010): Comparison of clinical features among youth with tic disorders, obsessive-compulsive disorder (OCD), and both conditions. Psychiatry Res $\underline{178}, 317-322$

Maina G, Albert U, Bogetto F, Ravizza L (1999): Obsessive-compulsive syndromes in older adolescents. Acta Psychiatr Scand 100, 447-450

March JS, Leonard HL (1996): Obsessive-compulsive disorder in children and adolescents: a review of the past 10 years. J Am Acad Child Adolesc Psychiatry 35, 1265-1273

Mathews CA, Jang KL, Hami S, Stein MB (2004): The structure of obsessionality among young adults. Depress Anxiety 20, 77-85

Merlo LJ, Storch EA, Murphy TK, Goodman WK, Geffken GR (2005): Assessment of pediatric obsessive-compulsive disorder: a critical review of current methodology. Child Psychiatry Hum Dev $\underline{36}, 195-214$

Moll GH, Rothenberger A (1999): Nachbarschaft von Tic und Zwang. Nervenarzt 70, 1-10

Moll GH, Eysenbach K, Woerner W, Banaschewski T, Schmidt MH, Rothenberger A (2000): Quantitative and qualitative aspects of obsessive-compulsive behaviour in children with attention-deficit hyperactivity disorder compared with tic disorder. Acta Psychiatr Scand 101, 389-394

Muris P, Merckelbach H, Clavan M (1997): Abnormal and normal compulsions. Behav Res Ther $\underline{35}, 249-252$

Nelson EC, Hanna GL, Hudziak JJ, Botteron KN, Heath AC, Todd RD (2001): Obsessivecompulsive scale of the child behavior checklist: specificity, sensitivity, and predictive power. Pediatrics $\underline{108}, 1-5$

Nomoto F, Machiyama Y (1990): An epidemiological study of tics. Jpn J Psychiatry Neurol $\underline{44}$, 649-655

Okasha A, Ragheb K, Attia AH, Seif El Dawla A, Okasha T, Ismail R (2001): Prevalence of obsessive compulsive symptoms (OCS) in a sample of Egyptian adolescents. Encephale 27, 8-14

Ozonoff S, Strayer DL, Mcmahon WM, Filloux F (1998): Inhibitory deficits in Tourette syndrome: a function of comorbidity and symptom severity. J Child Psychol Psychiatry $\underline{39}$, 1109-1118

Pappert EJ, Goetz CG, Louis ED, Blasucci L, Leurgans S (2003): Objective assessments of longitudinal outcome in Gilles de la Tourette's syndrome. Neurology 61, 936-940

Pauls DL, Raymond CL, Stevenson JM, Leckman JF (1991): A family study of Gilles de la Tourette syndrome. Am J Hum Genet $\underline{48}, 154-163$

Pelchat ML (2002): Of human bondage. Food craving, obsession, compulsion, and addiction. Physiol Behav $\underline{76}, 347-352$.

Peterson BS, Leckman JF (1998): The temporal dynamics of tics in Gilles de la Tourette syndrome. Biol Psychiatry 44, 1337-1348

Peterson BS, Pine DS, Cohen P, Brook JS (2001): Prospective, longitudinal study of tic, obsessivecompulsive, and attention-deficit/hyperactivity disorders in an epidemiological sample. $\mathrm{J}$ Am Acad Child Adolesc Psychiatry 40, 685-695

Pollak Y, Benarroch F, Kanengisser L, Shilon Y, Benpazi H, Shalev RS, Gross-Tsur V (2009): Tourette syndrome-associated psychopathology: roles of comorbid attention-deficit hyperactivity disorder and obsessive-compulsive disorder. J Dev Behav Pediatr 30, 413-419

Purdon C, Clark DA (1993): Obsessive intrusive thoughts in nonclinical subjects. Part I. Content and relation with depressive, anxious and obsessional symptoms. Behav Res Ther 31 , 713-720

Rachman S, De Silva P (1978): Abnormal and normal obsessions. Behav Res Ther 16, 233-248 
Rampello L, Alvano A, Battaglia G, Bruno V, Raffaele R, Nicoletti F (2006): Tic disorders: from pathophysiology to treatment. J Neurol 253, 1-15

Rasmussen SA, Eisen JL (1990): Epidemiology of obsessive compulsive disorder. J Clin Psychiatry 51 Suppl, 10-14

Rassin E, Muris P (2007): Abnormal and normal obsessions: a reconsideration. Behav Res Ther $\underline{45}$, $1065-1070$

Reddy H, Lassonde M, Bemasconi N, Bemasconi A, Matthews PM, Andermann F, Amold DL (2000): A fMRI study of the lateralization of motor cortex activation in acallosal patients. Neuroreport 11, 2409-2413

Robertson MM (2000): Tourette syndrome, associated conditions and the complexities of treatment. Brain $\underline{123}, 425-462$

Roessner V, Becker A, Banaschewski T, Rothenberger A (2005): Tic disorders and obsessive compulsive disorder: where is the link? J Neural Transm Suppl 69, 69-99

Roessner V, Becker A, Banaschewski T, Rothenberger A (2007): Psychopathological profile in children with chronic tic disorder and co-existing ADHD: additive effects. J Abnorm Child Psychol 35, 79-85

Roessner V, Plessen KJ, Rothenberger A, Ludolph AG, Rizzo R, Skov L, Strand G, Stern JS, Termine C, Hoekstra PJ et al. (2011): European clinical guidelines for Tourette syndrome and other tic disorders. Part II: pharmacological treatment. Eur Child Adolesc Psychiatry 20, 173-196

Rosenberg LA, Harris JC, Singer HS (1984): Relationship of the child behavior checklist to an independent measure of psychopathology. Psychol Rep 54, 427-430

Rothenberger A, Banaschewski T: Tic disorders; in: A Clinician's Handbook of Child and Adolescent Psychiatry; hrsg. v. Gillberg C, Harrington R, Steinhausen HC; Cambridge University Press, New York 2006, 598-624

Salkovskis PM (1989): Cognitive-behavioural factors and the persistence of intrusive thoughts in obsessional problems. Behav Res Ther 27, 677-684

Sass H, Wittchen HU, Zaudig M, Houben I: Diagnostisches und Statistisches Manual Psychischer Störungen DSM-IV. 4. Auflage; Hogrefe, Göttingen 2003

Sasson Y, Zohar J, Chopra M, Lustig M, Iancu I, Hendler T (1997): Epidemiology of obsessivecompulsive disorder: a world view. J Clin Psychiatry 58 Suppl 12, 7-10

Schmeck K, Poustka F, Dopfner M, Pluck J, Berner W, Lehmkuhl G, Fegert JM, Lenz K, Huss M, Lehmkuhl U (2001): Discriminant validity of the child behaviour checklist CBCL-4/18 in German samples. Eur Child Adolesc Psychiatry 10, 240-247

Shapiro AK, Shapiro E (1981): The treatment and etiology of tics and Tourette syndrome. Compr Psychiatry 22, 193-205

Simonds LM, Elliott SA (2001): OCD patients and non-patient groups reporting obsessions and compulsions: phenomenology, help-seeking, and access to treatment. $\mathrm{Br} \mathrm{J}$ Med Psychol 74, 431449

Singer HS (2000): Current issues in Tourette syndrome. Mov Disord 15, 1051-1063

Singer HS, Rosenberg LA (1989): Development of behavioral and emotional problems in Tourette syndrome. Pediatr Neurol $\underline{5}, 41-44$

Spencer T, Biederman J, Harding M, O'donnell D, Wilens T, Faraone S, Coffey B, Geller D (1998): Disentangling the overlap between Tourette's disorder and ADHD. J Child Psychol Psychiatry $\underline{39}, 1037-1044$

Stefanoff P, Wolanczyk T, Gawrys A, Swirszcz K, Stefanoff E, Kaminska A, Lojewska-Bajbus M, Mazurek B, Majewska-Stefaniak A, Mikulska J et al. (2007): Prevalence of tic disorders among schoolchildren in Warsaw, Poland. Eur Child Adolesc Psychiatry $\underline{3}, 171-178$

Stein MB, Forde DR, Anderson G, Walker JR (1997): Obsessive-compulsive disorder in the community: an epidemiologic survey with clinical reappraisal. Am J Psychiatry 154, 1120-1126

Steinhausen HC: Definition und Klassifikation; in: Handbuch ADHS; hrsg. v. Steinhausen Hc, Rothenberger A, Döpfner M; Kohlhammer, Stuttgart 2010 a, 17-28 
Steinhausen HC: Epidemiologie; in: Handbuch ADHS; hrsg. v. Steinhausen Hc, Rothenberger A, Döpfner M; Kohlhammer, Stuttgart 2010 b, 29-40

Stephens RJ, Sandor P (1999): Aggressive behaviour in children with Tourette syndrome and comorbid attention-deficit hyperactivity disorder and obsessive-compulsive disorder. Can J Psychiatry $\underline{44}, 1036-1042$

Stewart SE, Geller DA, Jenike M, Pauls D, Shaw D, Mullin B, Faraone SV (2004): Long-term outcome of pediatric obsessive-compulsive disorder: a meta-analysis and qualitative review of the literature. Acta Psychiatr Scand 110, 4-13

Storch EA, Murphy TK, Bagner DM, Johns NB, Baumeister AL, Goodman WK, Geffken GR (2006): Reliability and validity of the Child Behavior Checklist Obsessive-Compulsive Scale. J Anxiety Disord 20, 473-485

Sukhodolsky DG, Do Rosario-Campos MC, Scahill L, Katsovich L, Pauls DL, Peterson BS, King RA, Lombroso PJ, Findley DB, Leckman JF (2005): Adaptive, emotional, and family functioning of children with obsessive-compulsive disorder and comorbid attention deficit hyperactivity disorder. Am J Psychiatry 162, 1125-1132

Swedo SE, Rapoport JL, Leonard H, Lenane M, Cheslow D (1989): Obsessive-compulsive disorder in children and adolescents. Clinical phenomenology of 70 consecutive cases. Arch Gen Psychiatry $\underline{46}, 335-341$

Taylor E, Dopfner M, Sergeant J, Asherson P, Banaschewski T, Buitelaar J, Coghill D, Danckaerts M, Rothenberger A, Sonuga-Barke E et al. (2004): European clinical guidelines for hyperkinetic disorder - first upgrade. Eur Child Adolesc Psychiatry 13 Suppl 1, I7-30

Termine C, Balottin U, Rossi G, Maisano F, Salini S, Di Nardo R, Lanzi G (2006): Psychopathology in children and adolescents with Tourette's syndrome: a controlled study. Brain Dev $\underline{28}, 69-75$

Thomsen PH (1994): Obsessive-compulsive disorder in children and adolescents. A study of phenomenology and family functioning in 20 consecutive Danish cases. Eur Child Adolesc Psychiatry $\underline{3}, 29-36$

Thomsen PH (1995): Obsessive-compulsive disorder in children and adolescents: predictors in childhood for long-term phenomenological course. Acta Psychiatr Scand 92, 255-259

Toro J, Curvera M, Osejo E, Salamero M (1992): Obsessive-compulsive disorder in children and adolescents: A clinical study. J Child Psychol Psychiatry 33, 1025-37

Tzang RF, Chang YC (2009): Behavior problems and subtypes of attention-deficit hyperactivity disorder with comorbidities. Kaohsiung J Med Sci 25, 530-536

Ulloa RE, Sanchez S, Sauceda JM, Ortiz S (2006): [Psychopathology associated to attention deficit hyperactivity disorder in school age children]. Actas Esp Psiquiatr 34, 330-335

Valleni-Basile LA, Garrison CZ, Jackson KL, Waller JL, Mckeown RE, Addy CL, Cuffe SP (1994): Frequency of obsessive-compulsive disorder in a community sample of young adolescents. J Am Acad Child Adolesc Psychiatry 33, 782-791

Van Grootheest DS, Bartels M, Cath DC, Beekman AT, Hudziak JJ, Boomsma DI (2007): Genetic and environmental contributions underlying stability in childhood obsessive-compulsive behavior. Biol Psychiatry $\underline{61}, 308-315$

Volk HE, Henderson C, Neuman RJ, Todd RD (2006): Validation of population-based ADHD subtypes and identification of three clinically impaired subtypes. Am J Med Genet B Neuropsychiatr Genet 141B, 312-318

Walitza S, Melfsen S, Jans T, Zellmann H, Wewetzer C, Warnke A (2011): Obsessive-compulsive disorder in children and adolescents. Dtsch Arztebl Int 108, 173-179

Walkup JT, Rosenberg LA, Brown J, Singer HS (1992): The validity of instruments measuring tic severity in Tourette's syndrome. J Am Acad Child Adolesc Psychiatry $\underline{31}$, 472-477

Wang HS, Kuo MF (2003): Tourette's syndrome in Taiwan: an epidemiological study of tic disorders in an elementary school at Taipei County. Brain Dev 25 Suppl 1, S29-31 
Weissman MM, Bland RC, Canino GJ, Greenwald S, Hwu HG, Lee CK, Newman SC, OakleyBrowne MA, Rubio-Stipec M, Wickramaratne PJ et al. (1994): The cross national epidemiology of obsessive compulsive disorder. The Cross National Collaborative Group. J Clin Psychiatry $\underline{55}$ Suppl, 5-10

Wewetzer C, Jans T, Muller B, Neudorfl A, Bucherl U, Remschmidt H, Warnke A, HerpertzDahlmann B (2001): Long-term outcome and prognosis of obsessive-compulsive disorder with onset in childhood or adolescence. Eur Child Adolesc Psychiatry 10, 37-46

Wewetzer C, Simons M, Konrad K, Walitza S, Herpertz-Dahlmann B: Zwangsstörungen; in: Entwicklungspsychiatrie; hrsg. v. Herpertz-Dahlmann B, Resch F, Schulte-Markwort M, Warnke A; Schattauer, Stuttgart 2007, 719-743

World Health Organisation: Multiaxial Classification of Child and Adolescent Psychiatric Disorders: The ICD-10 Classification of Mental and Behavioural Disorders in Children and Adolescents; Cambridge University Press, Cambridge 1996

Zohar AH, Pauls DL, Ratzoni G, Apter A, Dycian A, Binder M, King R, Leckman JF, Kron S, Cohen DJ (1997): Obsessive-compulsive disorder with and without tics in an epidemiological sample of adolescents. Am J Psychiatry 154, 274-276 
Acknowledgments

First I would like to thank Prof. Dr. A. Rothenberger for giving me the opportunity to write this dissertation and for his contributions and ideas.

I would also like to thank Prof. Dr. V. Roessner for his valuable mentoring throughout the entire thesis. I also thank Dr. A. Becker for his assistance, especially with the statistics.

Finally I would like to thank my husband, Dr. Hannes Bielas, for his revision, encouragement and advice. 